\title{
Superhard CrN/MoN films with multilayer architecture
}

A.D. Pogrebnjak ${ }^{1}$, V.M. Beresnev ${ }^{2}$, O.V. Bondar ${ }^{1}$, B.O. Postolnyi ${ }^{1,3}$, K. Zaleski ${ }^{4}$, E. Coy ${ }^{4}$, S. Jurga $^{4}$, M.O. Lisovenko ${ }^{1}$, P. Konarski ${ }^{5}$, L. Rebouta ${ }^{6}$, J.P. Araujo ${ }^{3}$

${ }^{1}$ Sumy State University, 2, Rymskogo-Korsakova st., 40007 Sumy, Ukraine

${ }^{2}$ V.N. Karazin Kharkiv National University, 4 Svobody Sq., Kharkiv, 61022, Ukraine

${ }^{3}$ IFIMUP and IN-Institute of Nanoscience and Nanotechnology, Department of Physics and Astronomy, Faculty of Sciences, University of Porto, 687, Campo Alegre st., 4169-007 Porto, Portugal

${ }^{4}$ NanoBioMedical Centre, Adam Mickiewicz University, 85, Umultowska st. 61-614 Poznań, Poland

${ }^{5}$ Tele and Radio Research Institute, 11, Ratuszowa st., 03-450 Warsaw, Poland

${ }^{6}$ Centre of Physics, University of Minho, Azurém, 4800-058 Guimarães, Portugal

\begin{abstract}
The main regularities of the formation of microstructure and properties of multilayer nanostructured $\mathrm{CrN} / \mathrm{MoN}$ films with periodically changing architecture of layers were considered. The transition metal nitride coatings with high hardness and wear resistance were obtained by vacuum-arc evaporation of the cathodes (Arc-PVD) in nitrogen atmosphere at several sets of predetermined deposition parameters. CrN/MoN multilayers were fabricated using constant nitrogen pressure of $0.4,0.09$ and $0.03 \mathrm{~Pa}$. All samples were divided into three main series depending on the values of bias voltage applied to the substrates $(-20,-150$ and $-300 \mathrm{~V})$. Each serial of samples contain multilayer films varying in the individual layer deposition time and, hence, thickness, which is in range from $1.7 \mu \mathrm{m}$ to $20 \mathrm{~nm}$.
\end{abstract}

The morphology of surface and microstructure of cross-sections were studied by scanning electron microscopy (SEM). Elemental composition and elemental depth profiles were characterised by energy-dispersive X-ray spectroscopy (EDS), secondary-ion mass spectrometry (SIMS), Rutherford backscattering spectrometry (RBS) and high-resolution transmission electron microscopy (HRTEM) EDS. Micro- and nanostructural analysis of the films was performed by X-ray diffractometry (XRD), grazing incidence XRD (GIXRD), in-plane XRD, electron backscatter diffraction (EBSD) and HRTEM selected area electron diffraction (SAED).

The main phases formed in films were two $\mathrm{CrN}$ and $\gamma-\mathrm{Mo}_{2} \mathrm{~N}$ nitride phases with cubic lattice of $\mathrm{NaCl}$ type and not significant volume of additional metastable MoN cubic phase depending on nitrogen pressure and bias voltage. The preferential orientation of planes changes from [311] to [111] and [200] with the increase of absolute value of bias voltage from $-20 \mathrm{~V}$ to $-150 \mathrm{~V}$ and $-300 \mathrm{~V}$ respectively. The size of nanograins in coatings with a nanometre bilayers thickness was about $12 \mathrm{~nm}$, while micro-deformation of nanocrystallites was about $0.5-0.6 \%$. Coatings with thin nanoscale bilayers have shown high hardness (38-42 GPa) and strong wear resistance, which makes them appropriate and promising for industrial applications as protective ones. The relations between deposition conditions and obtained composition, structure and features were studied. The best parameters and deposition conditions were discussed as recommended to achieve superior mechanical and physical properties of coatings with long lifetime and applicable for harsh environment.

Keywords: nitrides, multilayers, structure, hard coatings, plasticity index, wear

\section{Introduction}

The fabrication of protective coatings by various deposition methods (chemical processes, physical vapor deposition, ion-assisted deposition) allows to solve plenty of problems in industry 
regarding approaches to improve wear and corrosion resistance, reduce friction, increase fatigue strength of cutting tools and mechanical details [1-9]. Among this variety of strengthening technologies, a special place is occupied by vacuum-arc deposition often named also as cathodic arc physical vapour deposition (Arc-PVD), which makes it possible to obtain coatings suitable for work under high temperatures and pressures, aggressive environment, high corrosion and intensive wear [9-17].

It is well known that nitride films based on transition and refractory metals are characterized by high hardness, high melting temperatures, good chemical and physical stability, which allow to use such coatings as protective ones. At the same time, the decrease of the grain size to the nanoscale range results in the increase of hardness from 25 to $40 \mathrm{GPa}$. One of the reasonable methods of modern material design is the creation of nanocomposite coatings consisting of small nanograins of one phase inside an amorphous or nanostructured phase of different composition. It allows to improve significantly the protective properties of deposited coatings. On the other hand, the design of multilayer coatings with different composition of bilayers (soft and solid phases) allows to reduce internal stresses and brittleness while high values of hardness from 30 to $45 \mathrm{GPa}$ are maintained [18-28]. One of the promising multilayer systems is the combination of chromium and molybdenum nitrides[29-34].

Atoms in crystal lattices of different thin layers in multi-layered films can be replaced at interfaces. This process results in the generation of strain energy proportional to the shear modulus of the material. The layers with different shear modulus prevent the movement of dislocations. Additionally, deviations or redistribution of dislocations and cracks at the grain boundaries help to increase the resistance of coatings. The multilayer structure reduces the influence of sublayer cracking and allows its employing under large dynamic loads. The alternation of nanometre-scale layers with different physical-mechanical characteristics allows to change significantly the properties of multilayer coatings, such as concentration of internal stresses, crack propagation and, hence, to increase the fracture toughness of such material. Chromium nitride exhibits high temperature stability and has lower friction coefficient than titanium nitride, the most widely used transition metal nitride since the late 1960s [35-38]. Initially high mechanical properties of $\mathrm{MoN}$, such as low friction and wear coefficients, in combination with high hardness and good adhesion, will complement the properties of monolayer CrN coatings, in particular the oxidation resistance [14,39-41].

This paper is aimed to create new nanocomposite multi-layered $\mathrm{MoN} / \mathrm{CrN}$ films and study their structure and properties. The focus is on the effect of bilayer thickness change from micro- to nanoscale range, and on the influence of different negative substrate bias voltage applied during deposition process. The research provides necessary information in order to select optimal parameters for the enhancement of physical-mechanical properties of considered protective coatings.

\section{Deposition and Characterisation Methods}

Polished stainless steel substrates with surface roughness up to $0.01 \mu \mathrm{m}$ were used for the deposition. The multilayer coatings were fabricated by vacuum-arc evaporation of molybdenum and titanium cathodes in nitrogen atmosphere using Bulat-6 unit [3],[18]. A principal scheme of the deposition system is shown in Fig. 1. The constant nitrogen pressure $\mathrm{p}_{\mathrm{N}}$ of $0.4,0.09$ and 0.03 
$\mathrm{Pa}$ was used in the chamber. Three series of samples were deposited with different bias voltages of $-20,-150$ and $-300 \mathrm{~V}$ applied to the substrate. The samples of each serial vary on deposition time of the individual layer, which is constant but twice reduced for each of the next sample of the coating, keeping the total deposition time constant ( 1 hour). The thickness of the coatings was from 8 to $14 \mu \mathrm{m}$. Detailed information about deposition conditions is presented in Table 1.

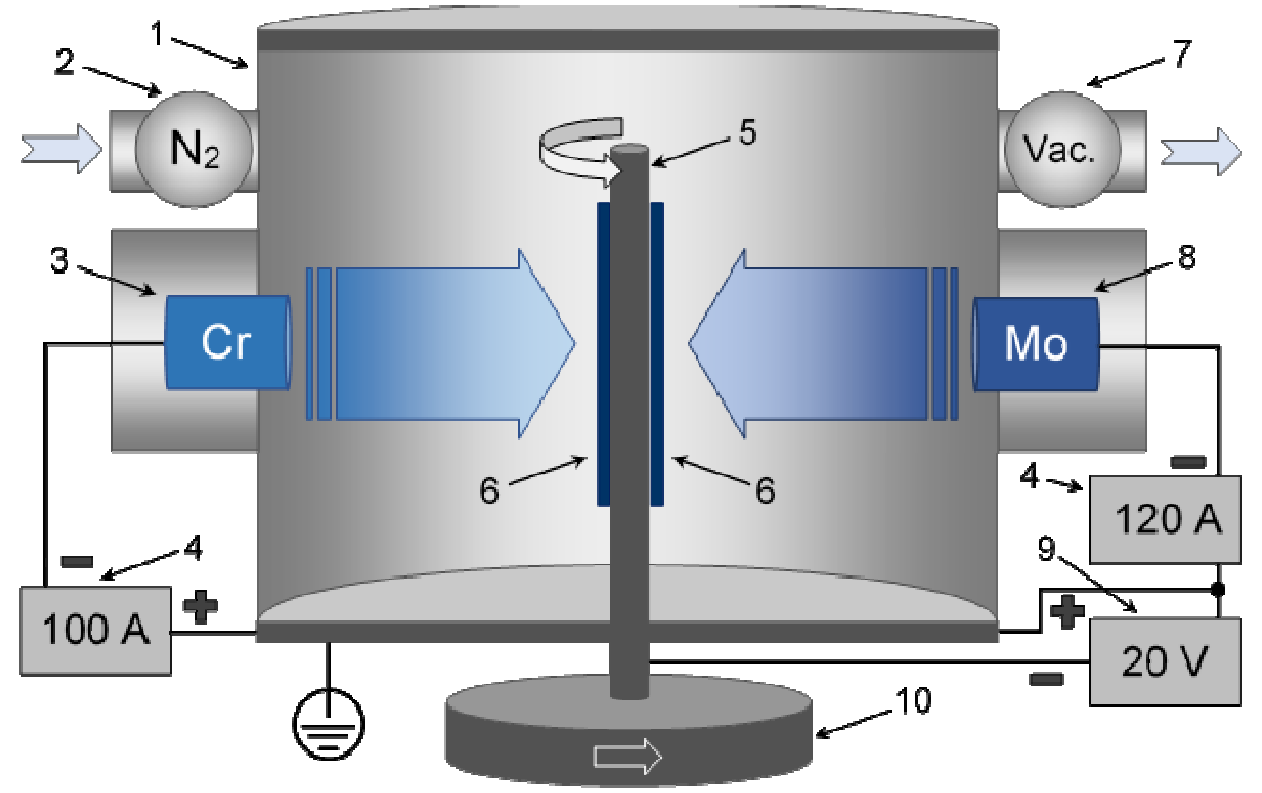

Figure 1. Principal scheme of vacuum-arc deposition system for multilayer films: 1 - vacuum chamber, 2 - nitrogen supply, 3 - chromium cathode, 4 - arc power supplies, 5 - substrate holder, 6 - substrates, 7 - molybdenum cathode, 8 - vacuum pump, 9 - substrate power supply, 10 - automatic rotation system for substrate holder.

Table 1. Deposition parameters of the MoN/CrN coatings. Arc current $\operatorname{Iarc}(\mathrm{Mo})=120 \mathrm{~A}$, $\operatorname{Iarc}(\mathrm{Cr})=100 \mathrm{~A}$, total deposition time $\mathrm{t}_{\text {tot }}=1 \mathrm{~h}, \mathrm{t}_{1}$ - one layer deposition time, $\mathrm{N}_{1}$ - number of layers, $\lambda$ - bilayer thickness. Samples marked with asterisk $(*)$ were deposited in a continuous rotation mode of the substrate holder.

\begin{tabular}{|c|c|c|c|c|c|c|}
\hline Series & $\begin{array}{l}\text { Sample } \\
\text { number }\end{array}$ & $\mathrm{p}_{\mathrm{N}}, \mathrm{Pa}$ & $\mathrm{t}_{1}, \mathrm{~s}$ & $\mathrm{~N}_{1}$ & $\lambda, \mu \mathrm{m}$ & $\mathrm{U}_{\mathrm{b}}, \mathrm{V}$ \\
\hline \multirow{6}{*}{1} & 1.1 & \multirow{6}{*}{0.4} & 300 & 12 & 2.26 & \multirow{6}{*}{-20} \\
\hline & 1.2 & & 150 & 25 & 1.18 & \\
\hline & 1.3 & & 80 & 45 & 0.60 & \\
\hline & 1.4 & & 40 & 88 & 0.25 & \\
\hline & 1.5 & & 20 & 180 & 0.12 & \\
\hline & 1.6 & & 10 & 354 & 0.044 & \\
\hline \multirow{6}{*}{2} & 2.1 & \multirow{5}{*}{0.4} & 300 & 12 & 2.85 & \multirow{6}{*}{-150} \\
\hline & 2.2 & & 150 & 25 & 1.39 & \\
\hline & 2.3 & & 80 & 45 & 0.69 & \\
\hline & 2.4 & & 40 & 88 & 0.32 & \\
\hline & 2.5 & & 20 & 180 & 0.14 & \\
\hline & $2.7^{*}$ & 0.09 & 150 & 22 & 0.25 & \\
\hline \multirow{7}{*}{3} & 3.1 & \multirow{6}{*}{0.4} & 300 & 11 & 3.5 & \multirow{7}{*}{-300} \\
\hline & 3.2 & & 150 & 22 & 1.55 & \\
\hline & 3.3 & & 80 & 44 & 0.74 & \\
\hline & 3.4 & & 40 & 88 & 0.36 & \\
\hline & 3.5 & & 20 & 180 & 0.15 & \\
\hline & 3.6 & & 10 & 354 & 0.075 & \\
\hline & $3.7^{*}$ & 0.03 & 22 & 150 & 0.19 & \\
\hline
\end{tabular}


The morphology of the surface and the cross-section structure were studied by scanning electron microscopy (SEM) and energy-dispersive X-ray spectroscopy (EDS) using Quanta 200 3D microscope and FEI Quanta 400 FEG Environmental SEM (ESEM). Most of the EDS analyses of multilayer films were performed on cross-section samples acquiring integral spectra from large area of all layers contained in the coating keeping equal number of $\mathrm{MoN}$ and $\mathrm{CrN}$ layers. Electron beam energy used in elemental composition analysis by EDS was $10 \mathrm{keV}$. The electron backscatter diffraction (EBSD) analysis was carried out using the unit of EDAX EBSD forward scatter detector system and high resolution DigiView III camera attached to the above mentioned ESEM. The method of secondary-ion mass spectrometry (SIMS) analysis was performed using SAJW-05 spectrometer equipped with Physical Electronics argon ion gun and QMA-410 Balzers quadrupole mass analyser. The structural-phase analysis was performed by X-ray diffractometry (XRD), including several low-angle XRD methods, such as grazing incidence XRD and in-plane XRD. The samples were exposed to $\mathrm{Cu}-\mathrm{K} \alpha$ radiation using Panalytical X'Pert Pro Multipurpose Diffractometer and high-resolution X-ray diffractometer Rigaku SmartLab. Rutherford backscattering spectrometry (RBS) was used to analyse the elemental depth profile of the coatings. A $1.4 \mathrm{MeV} \mathrm{He}+$ ion beam and normal incidence was used in the experiments. Spectra were collected with a detector with an energy resolution of $16 \mathrm{keV}$ installed at $170^{\circ}$ to the beam direction. Element concentration through the depth profiles and layers thickness were determined by computer simulation in SIMNRA assuming bulk density of $5.8 \mathrm{~g} / \mathrm{cm}^{3}$ and $9.2 \mathrm{~g} / \mathrm{cm}^{3}$ for CrN and MoN respectively.

The hardness and Young's modulus (elastic modulus) were measured by micro-indentation method with a Vickers diamond pyramid at load range from 200 to $980 \mu \mathrm{N}$. Tribological tests and measurements were performed with the ball-on-disc test by spherical $\mathrm{Al}_{2} \mathrm{O}_{3}$ counterbody. The alumina ball (static element) has diameter of $10 \mathrm{~mm}$ and $R_{a}=0.03 \mu \mathrm{m}$. The load was $20 \mathrm{~N}$ and sliding speed was about $0.2 \mathrm{~m} / \mathrm{s}$. The wear rate was evaluated using the results of the ballon-disc experiment performed at dry friction conditions on a distance up to $1000 \mathrm{~m}$. It was calculated as wear volume divided by sliding distance and normal load [59,60].

\section{Results and Discussion}

\subsection{Multilayer Design and Chemical Composition}

The cross-sections SEM analysis was used for the samples to study the cross-sectional morphology in the films and their multilayer structure. In results, the calculated values of bilayer and total thickness of the deposited films are given in Table 1 and they are in accordance to the expected ones. The selected SEM images of the multilayer CrN/MoN coatings with bilayer thickness of $1.18 \mu \mathrm{m}$ and $44 \mathrm{~nm}$ are presented in Fig. 2. The samples demonstrate well defined multilayer structure with distinct interfaces and good planarity of the individual layers. It should be noted that the MoN layers (bright in the SEM images) are slightly thinner than the CrN layers (dark areas) due to the different cathodes evaporation and nitride films deposition rates. Especially it is more evident on the samples with thicker bilayers (see Fig. 2 (b)) rather than on thinner ones (with shorter deposition time per layer). 


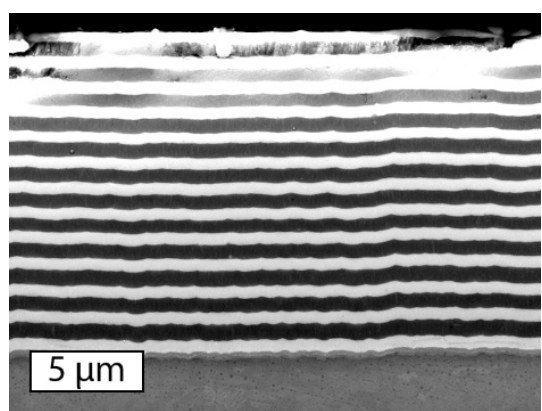

(a)

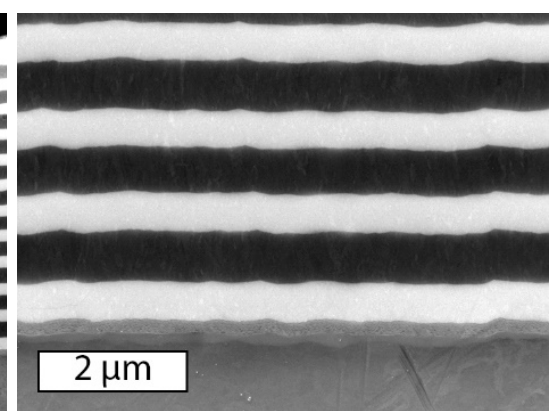

(b)

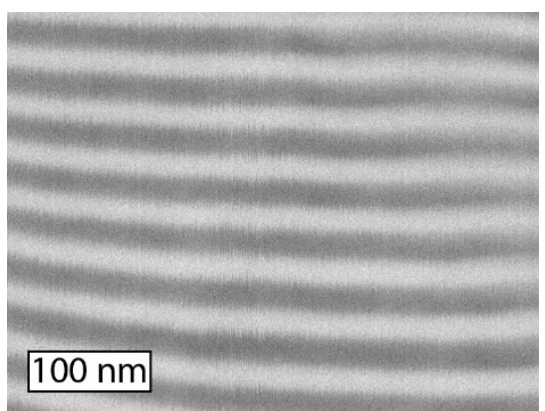

(c)

Figure 2 - SEM-images of polished cross-sections of multilayer CrN/MoN coatings: (a) and (b) - sample 1.2; (c) sample 1.6.

Figure 3 represents the typical EDS-spectrum of $\mathrm{CrN} / \mathrm{MoN}$ multilayer films deposited at $\mathrm{U}_{\mathrm{b}}=$ $-150 \mathrm{~V}$ (Series 2, sample 2.1). It shows almost equiatomic elemental composition of the metal components: $\mathrm{Mo} / \mathrm{Cr}$ atomic ratio varies from 0.90 to 0.93 . Similar results were obtained for other series of samples deposited at different bias voltage $\left(\mathrm{U}_{\mathrm{b}}=-20,-150\right.$ and $\left.-300 \mathrm{~V}\right)$. The slight prevalence of chromium atoms may be explained by little difference in sputtering yields of Mo and $\mathrm{Cr}$ cathodes, as well as in $\mathrm{CrN}$ and $\mathrm{MoN}$ deposition rates. But despite this, the thicknesses of the alternating layers should be practically equal, which is confirmed by the presented SEMimages (Fig. 2). Unfortunately, while EDS technique is appropriate for fast and precise evaluation of metals concentration, it is not sensitive enough for light elements, such as Nitrogen, and its ratio may be underestimated. In this way, for evaluation of light elements composition it is preferably to use RBS, SIMS, WDS or other experiments. Nevertheless, the different bias potential $U_{b}$ doesn't affect significantly the atomic concentration of nitrogen, which ratio in the layers varies from 0.4 to 0.6 (for $\mathrm{p}_{\mathrm{N}}=0.4 \mathrm{~Pa}$ ), due to the transformation of vacancies as a result of secondary sputtering and re-deposition effects during ion bombardment $[18,42]$. The dependence of nitrogen ratio on nitrogen pressure in the chamber during deposition is clearer end more evident. With the $\mathrm{p}_{\mathrm{N}}$ decrease to 0.09 or $0.03 \mathrm{~Pa}$ the $\mathrm{N}$ ratio drops to $0.1-0.2$.

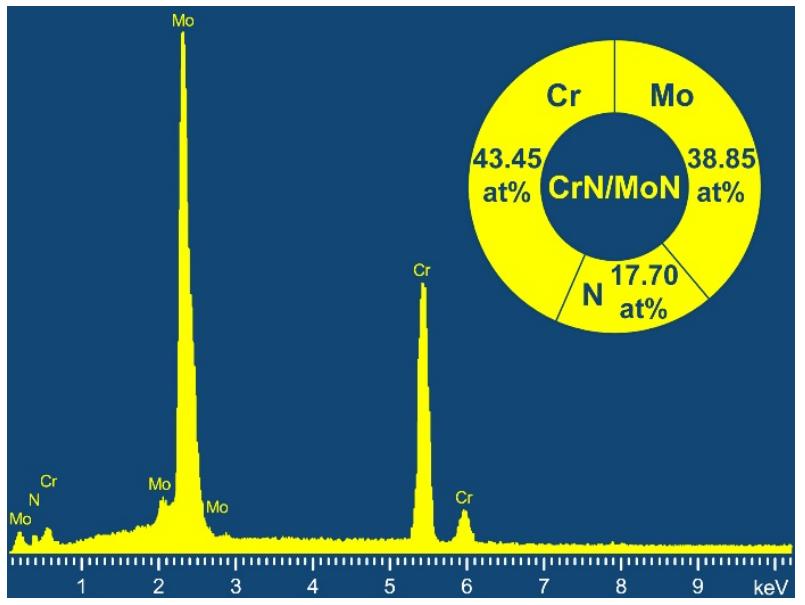

Figure 3 - EDS spectrum and elemental analysis of CrN/MoN multilayer film, sample 2.1.

To complement the above-mentioned results, the RBS analysis was used, which is a highprecision non-destructive method and may serve as a reference. Since the beam has a diameter of about $1 \mathrm{~mm}$, the averaging of layers thickness occurs on a large area. The obtained depth profiles of $\mathrm{Cr}$, Mo and $\mathrm{N}$ elements demonstrate a sufficient uniformity of the $\mathrm{CrN}$ and $\mathrm{MoN}$ layers in 
analysed area $[23,43]$. The RBS depth profiling has been proved as a powerful tool to evaluate the multilayer structure and chemical composition of considered films.

The results of RBS analysis for CrN/MoN films of Series $3\left(\mathrm{U}_{b}=-300 \mathrm{~V}\right)$ with different bilayer thickness are presented in Fig. 4. For the first sample (Fig. 4 (a)) with the thicker layers it was possible to obtain the spectrum of only the first MoN top layer (analysed depth is $1.73 \mu \mathrm{m}$ ): Mo $\approx 50$ at. $\%$ and $\mathrm{N} \approx 50$ at.\%. For rest of the samples of Series 3 with thinner layer thickness the several periods were clearly observed. Fig. 4 (b) shows the spectrum of sample 3.4. The edge of

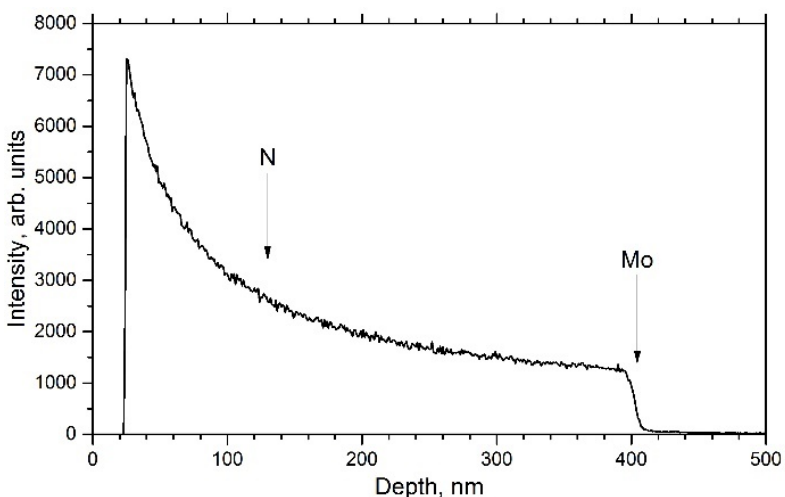

(a)

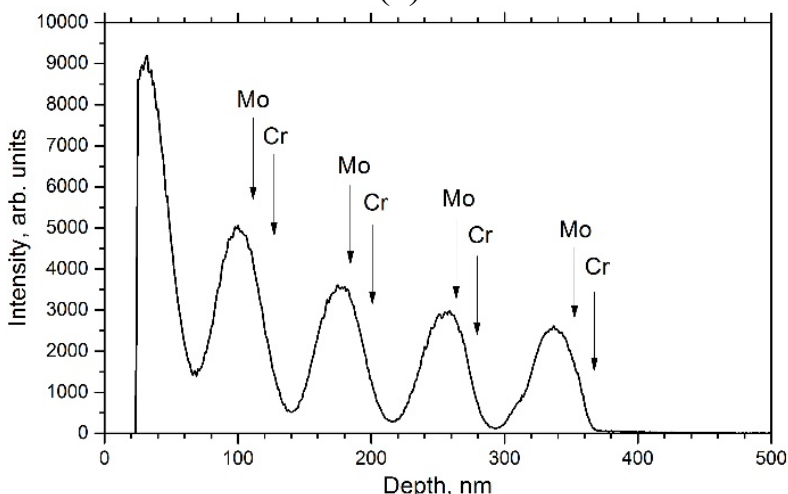

(c)

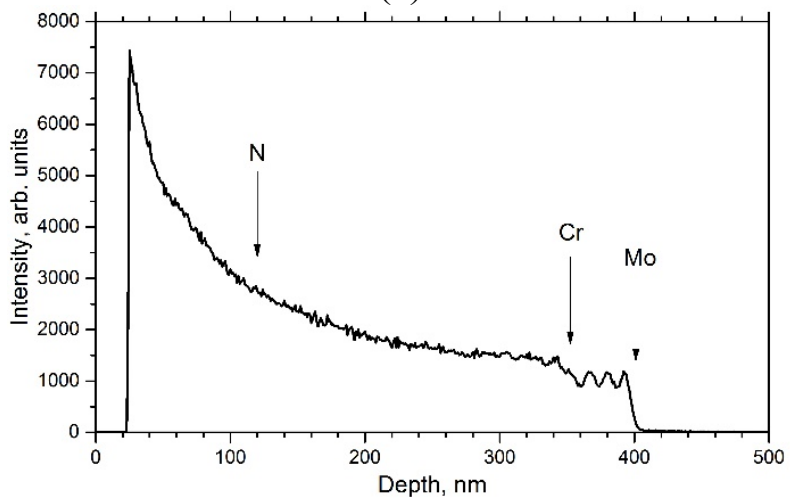

(e)

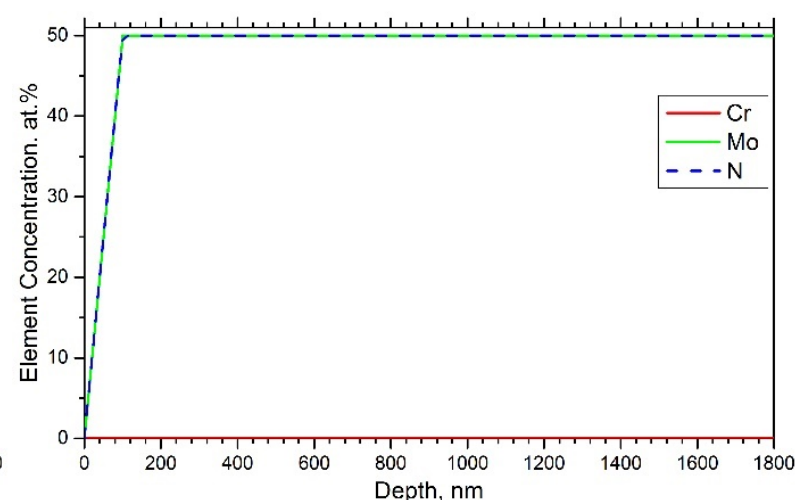

(b)

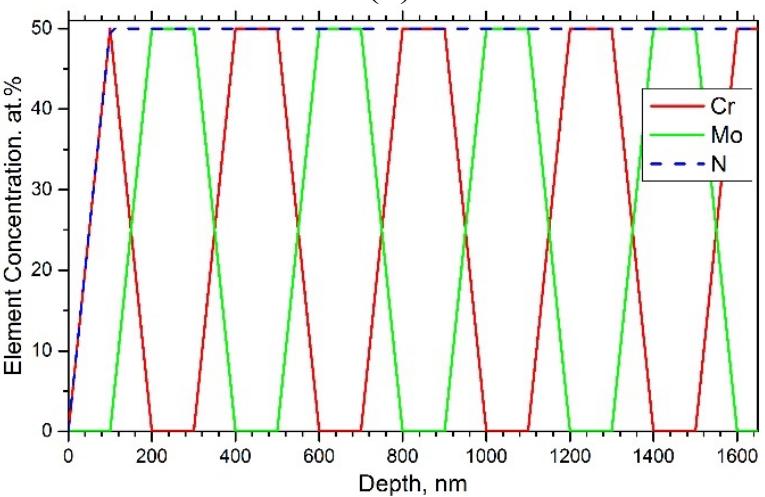

(d)

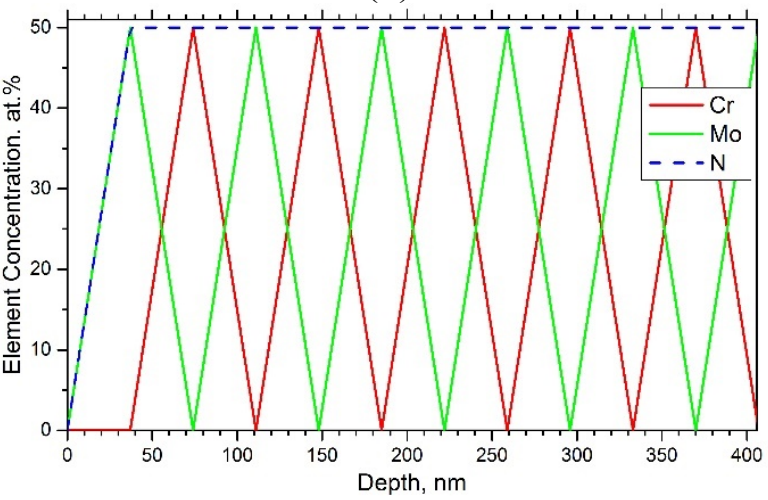

(f)

Figure 4 - RBS spectra (left) and depth profiles (right) of elements for samples 3.1 (a, b), 3.4 (c, d) and 3.6 (e, f)

the first peak corresponds to $\mathrm{Cr}$, thus $\mathrm{CrN}$ is the top surface layer of the coating. Then the front of Mo follows, imposed on $\mathrm{Cr}$ front, i.e. the front of Mo is shifted by the width of Cr. The peaks on the RBS spectrum (Fig. 4 (c)) correspond to the CrN/MoN period of the multilayer film. The beam of $\mathrm{He}^{+}$ions used in the experimant has passed the depth of $5 \mathrm{CrN} / \mathrm{MoN}$ bilayers, where calculated thickness of $\mathrm{CrN}$ layer was $189 \mathrm{~nm}$ and $170 \mathrm{~nm}$ for MoN, which results in the bilayer 
thickness of $359 \mathrm{~nm}$. Fig. 4 (e) and (f) present the results of RBS analysis for coatings with the thinnest layers (sample 3.6). The spectrum clearly displays the elemental composition of the first three bilayers. The first three peaks correspond to Mo and the fourth is $\mathrm{Cr}$ shifted towards the lower channel numbers by the thickness of Mo. The next $\mathrm{Cr}$ and Mo peaks are overlapped due to the small thickness of the individual layers. The thickness of MoN layers is $37 \mathrm{~nm}$ and the thickness of CrN layers is $38 \mathrm{~nm}$. Thus, the bilayer thickness $(\lambda)$ is $75 \mathrm{~nm}$. Results of bilayer thickness evaluation for all measured $\mathrm{CrN} / \mathrm{MoN}$ films of Series 3 by RBS are presented in Table 1.

The results of SIMS analysis of elemental composition and multilayer structure of CrN/MoN films for sample 3.6 with the thinnest layers are shown in Fig. 5. Two acquisitions were performed with ion beam energy of 5 and $1.72 \mathrm{keV}$ (Fig. 5 (a) and (b) respectively). SIMS is a destructive method of quantitative elemental analysis through the depth of coating. With $5 \mathrm{keV}$ ion beam the crater has reached the size of $2 \times 2 \mathrm{~mm}$ and almost 1 micron of depth. Due to the reduced ion mixing effect the lower energy of ion beam of $1.72 \mathrm{keV}$ gives better resolution but significantly lower sputtering rate: $0.65 \mathrm{~nm} / \mathrm{min}$ against $6.3 \mathrm{~nm} / \mathrm{min}$ of the previous acquisition. From the elemental profiles it is clearly seen that the layers of chromium nitride have higher nitrogen content than molybdenum nitride layers: the high intensity of the nitrogen peaks coincides with the positions of the chromium peaks. These results are in good correlation with the results of X-ray diffraction analysis of phase composition presented below.

Also, the SIMS analysis demonstrates a clear modulation in the composition of the multilayer coatings. Fig. 5 (c) shows the multilayer structure of coatings as a plot of normalized $\mathrm{Cr}$ and Mo ion current divided by their sum. This relation can describe a concentration of MoN and $\mathrm{CrN}$. The thickness of consecutive bilayers remains constant and is equal to $71 \mathrm{~nm}$, where the thickness of $\mathrm{CrN}$ and $\mathrm{MoN}$ layers is 36 and $35 \mathrm{~nm}$ respectively. The first 5 periods from the surface of the CrN/MoN films are well defined, while deeper layers are not resolved due to the ion mixing, surface defects and roughness of the coatings. The increase and decrease in the nitrogen content in the gas stream indicates a partial conversion of the $\mathrm{Cr}$ metallic signal to the Cr-N compound caused by the nitrogen flow, thus forming multilayer coatings with high mechanical properties [44-46].

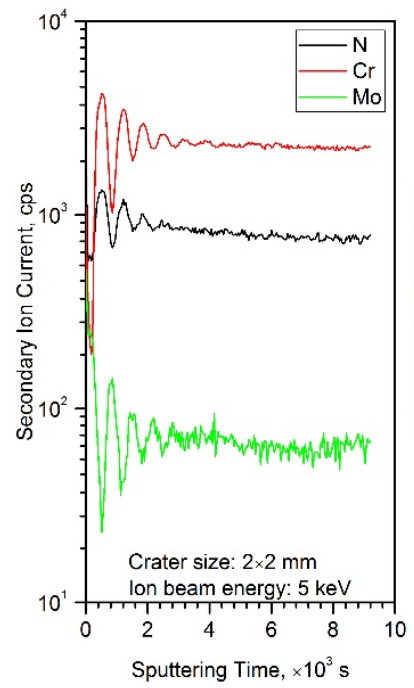

(a)

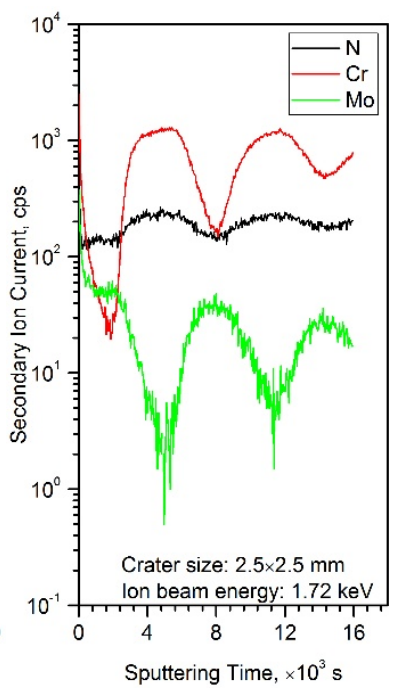

(b)

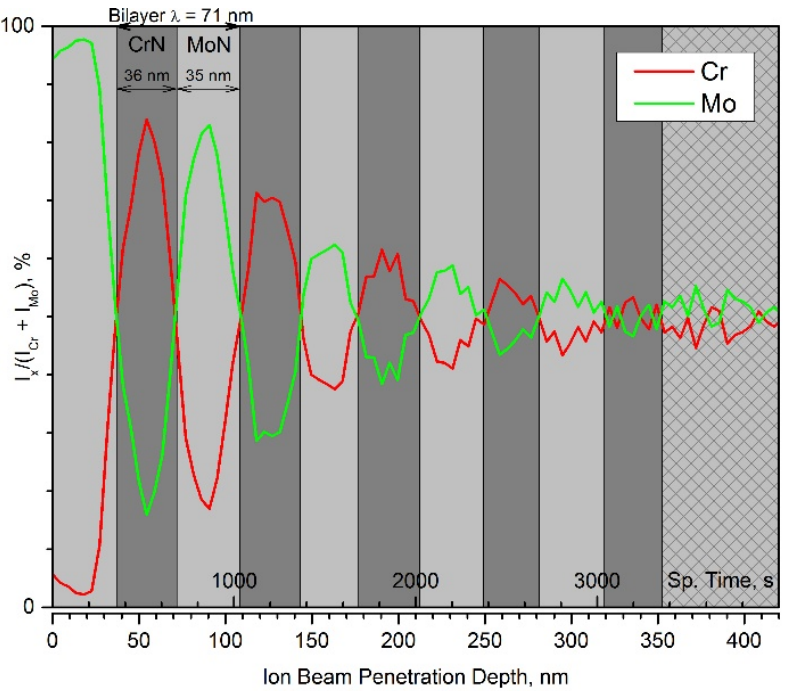

(c)

Figure 5 - Results of SIMS analysis of CrN/MoN coatings (sample 3.6). 


\subsection{Micro- and Nanostructure}

Fig. 6 (a)-(c) show the XRD patterns for the $\mathrm{CrN} / \mathrm{MoN}$ multilayer coatings deposited with negative $U_{b}$ of $-20,-150$ and $-300 \mathrm{~V}$. The patterns demonstrate how significant is the influence of bias voltage on the deposited material structure. The identical cubic lattice structure of $\mathrm{CrN}$ and $\mathrm{Mo}_{2} \mathrm{~N}$ with $\mathrm{Fm} 3 \mathrm{~m}$ space group and similar lattice parameter of $0.4163 \mathrm{~nm}\left(\mathrm{Mo}_{2} \mathrm{~N}\right)$ and $0.4140 \mathrm{~nm}(\mathrm{CrN})$ allow to form multilayer $\mathrm{CrN} / \mathrm{MoN}$ coatings with small internal stresses at interfaces. On the other hand, it leads to the difficulties with distinguishing of $\mathrm{CrN}$ and MoN diffraction peaks on XRD spectra. The diffraction patterns of chromium nitride and molybdenum nitride phases are well known. Nevertheless, different deposition conditions may cause the formation of several hexagonal and cubic phases of both nitrides. The comparison of Fig. 6 (a) and (b) shows that for bias potential $U_{b}=-20 \mathrm{~V}$ the same type of crystal lattice of structural type $\mathrm{B} 1$ (fcc of $\mathrm{NaCl}$ type) is formed in the coatings, which is typical for $\mathrm{CrN}$ and $\gamma-\mathrm{Mo}_{2} \mathrm{~N}$. The predominant [311] orientation of crystallite growth perpendicular to the formed planes was observed from the relative intensification of the corresponding diffraction peaks $[47,48]$.

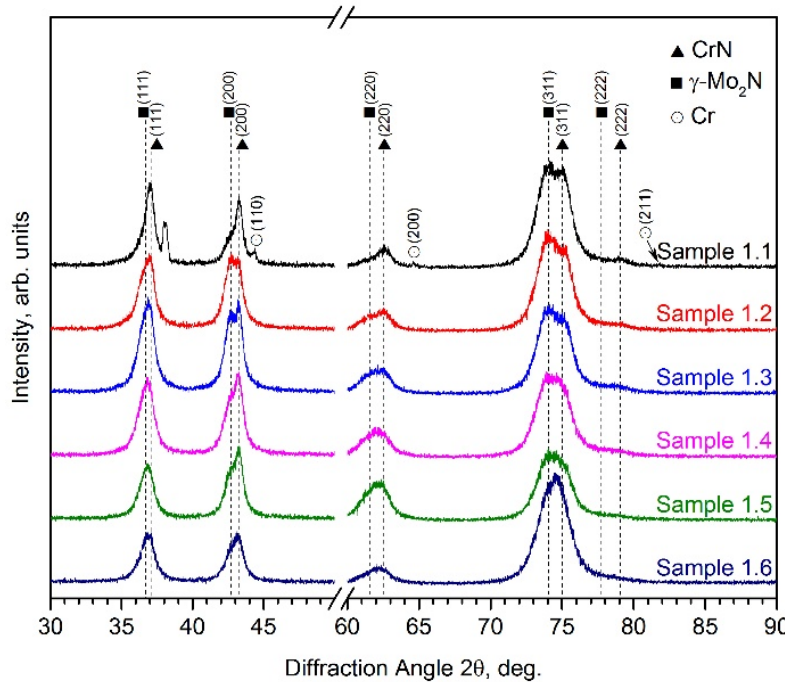

(a)

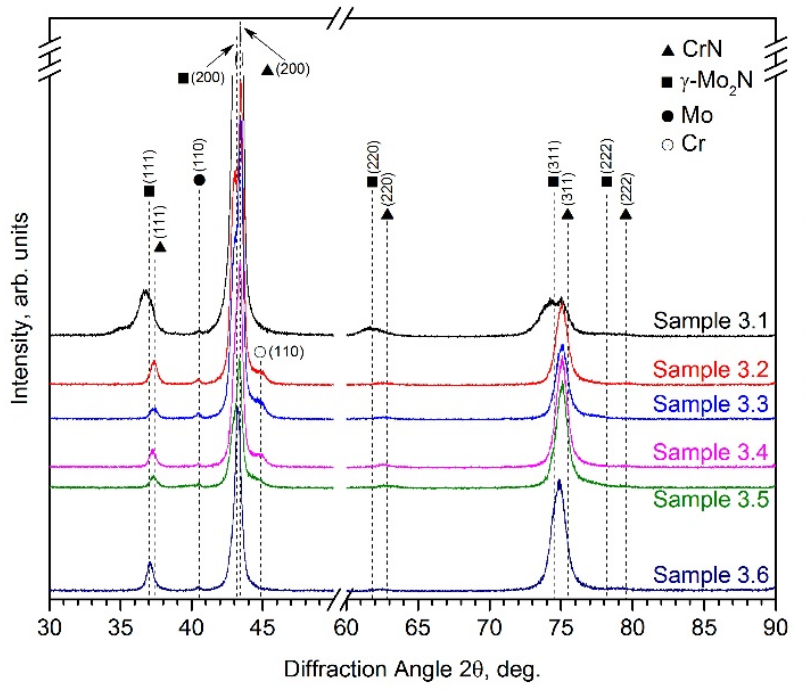

(c)

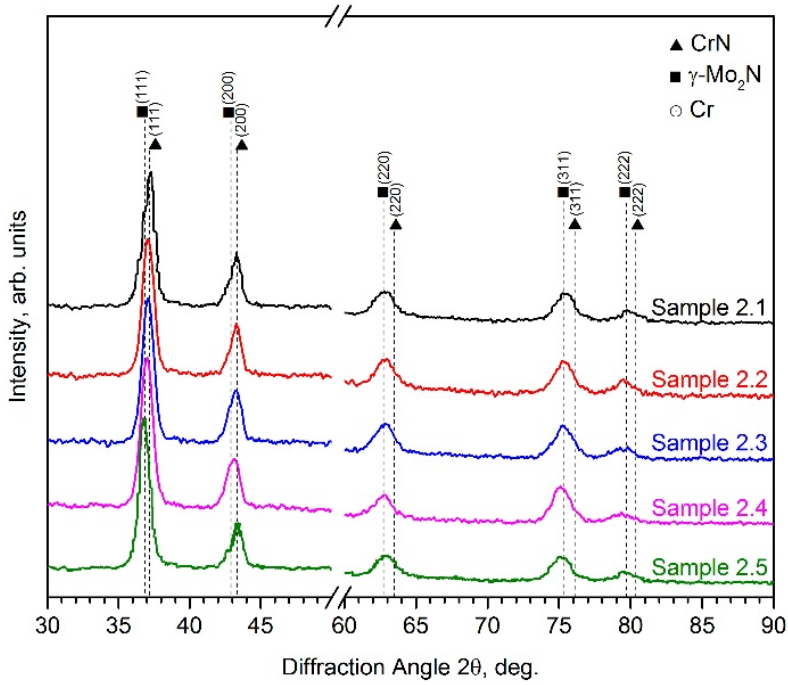

(b)

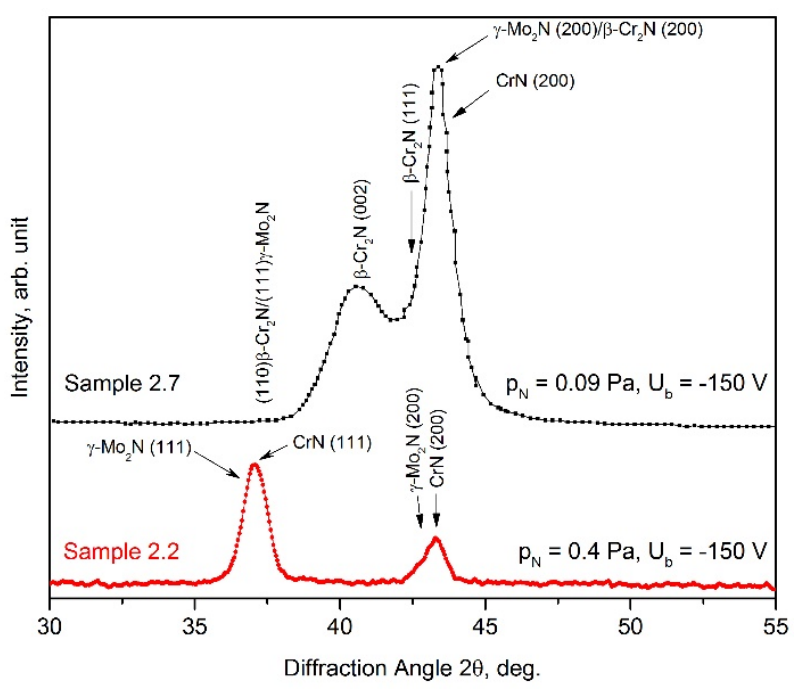

(d)

Figure 6 - X-ray diffraction patterns (theta/2theta) of $\mathrm{CrN} / \mathrm{MoN}$ multi-layered coatings: spectra for samples deposited at negative bias voltage of $-20 \mathrm{~V}(\mathrm{a}),-150 \mathrm{~V}(\mathrm{~b}),-300 \mathrm{~V}$ (c) and comparison of samples deposited at different nitrogen pressure (d). 
The supply of higher negative bias potential $U_{b}=-150 \mathrm{~V}$ to the substrate forms a different type of texture with [111] direction, which intensity grows with the increase of bilayer thickness. However, it doesn't lead to an explicit separation of the diffraction peaks from the corresponding phases of two nitride layers at high angles, which indicates the formation of a solid solution on interlayer zones and thin layers. With a subsequent increase of the absolute value of the applied bias potential to $U_{b}=-300 \mathrm{~V}$ (Fig. 6 (c)) the texture changes significantly to [200] direction of crystallite planes in $\mathrm{CrN} / \mathrm{MoN}$ multilayer films. Such types of textures appear due to the relative decrease of the nitrogen content in the coatings when the absolute values of negative bias voltage applied to the substrate increase. The presence of structures with coincident values of interplanar distance in zones of interlayer interfaces certifies their interdependent growth [39,49], [39], [40]. The reduction of nitrogen pressure $\mathrm{p}_{\mathrm{N}}$ from 0.4 to $0.09 \mathrm{~Pa}$ leads to the formation of $\beta-\mathrm{Cr}_{2} \mathrm{~N}$ hexagonal phase and $\gamma-\mathrm{Mo}_{2} \mathrm{~N}$ FCC-type phase with interplanar spacings for (110) $\beta-\mathrm{Cr}_{2} \mathrm{~N} /(111) \gamma-\mathrm{Mo}_{2} \mathrm{~N}$ (coincident diffraction peak) and $(002) \beta-\mathrm{Cr}_{2} \mathrm{~N} /(200) \gamma-\mathrm{Mo}_{2} \mathrm{~N}$ planes (two clearly separate peaks). This evolution of the texture in $\mathrm{CrN} / \mathrm{MoN}$ films with decreasing of nitrogen pressure is shown in Fig. 6 (d). Also, at $\mathrm{p}_{\mathrm{N}}=0.09 \mathrm{~Pa}$ and increase of absolute value of bias potential $U_{b}$ to $-150 \mathrm{~V}$ it is observed the preferential growth of crystallites in [002] and [200] directions for $\beta-\mathrm{Cr}_{2} \mathrm{~N}$ and $\gamma-\mathrm{Mo}_{2} \mathrm{~N}$ phases respectively, which leads to the increase of interlayer mismatch.

The analysed XRD spectra demonstrate the shift of the diffraction peaks to the side of lower angles which indicates the increase of interplanar distances and, hence, lattice constants in direction normal to the surface. This is a sign of residual stresses presented in the deposited coatings.

To identify the diffraction patterns of individual layers and check more precisely their structure and phase composition the methods of low-angle X-ray diffraction were used: in-plane XRD and asymmetrical scans included GIXRD. Application of such approach where the angle between Xray incident beam and sample (omega, $\omega$ ) remains fixed at some value while only the detector

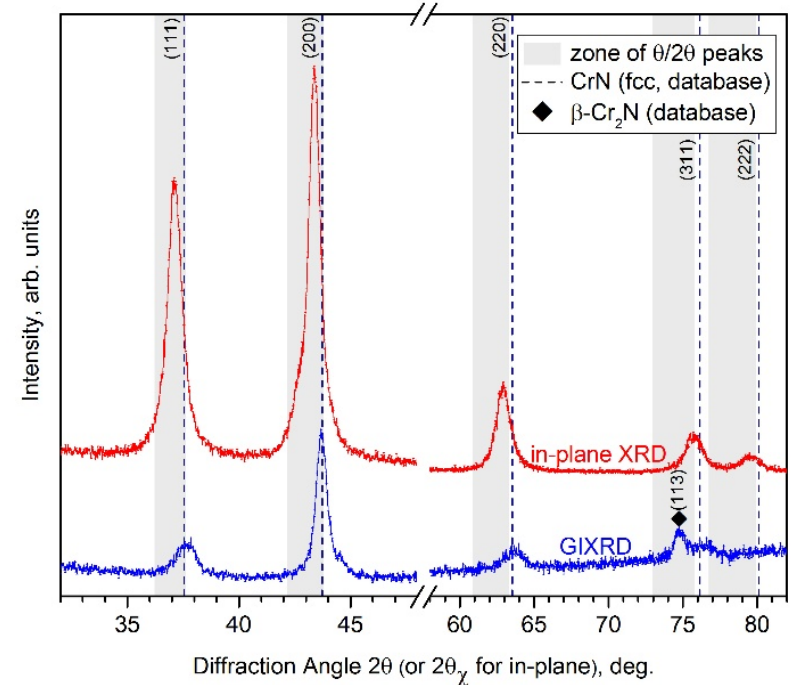

(a)

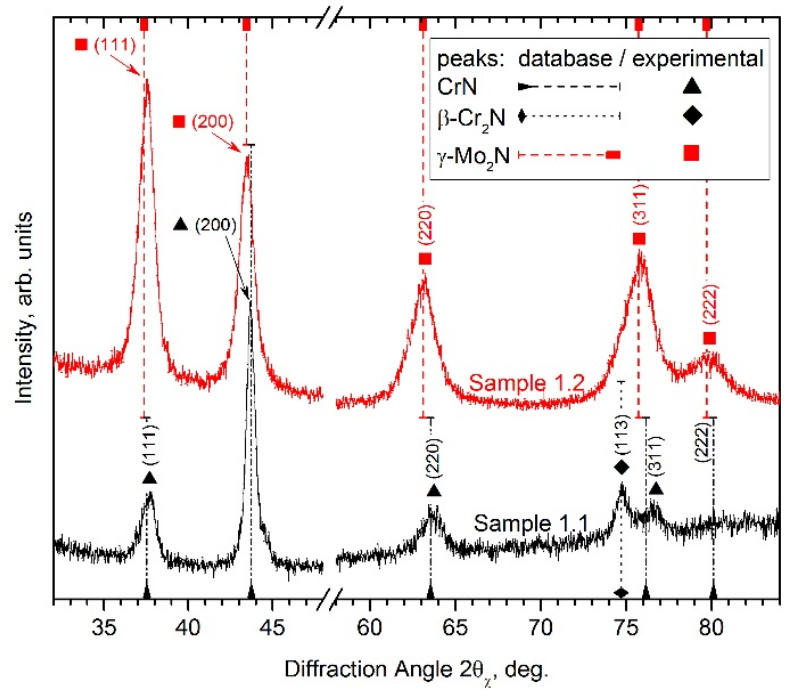

(b)

Figure 7 - X-ray diffraction patterns taken in several low-angle modes. (a) GIXRD and in-plane XRD spectra taken for sample 1.1 at incident angle $\omega=0.4^{\circ}$. Grey zones show the position of experimental diffraction peaks of $\theta / 2 \theta$ scan. (b) In-plane XRD for samples 1.1 (top layer $\mathrm{CrN}$ ) and 1.2 (top layer MoN) with $\omega=0.6^{\circ}$. 
moves during the acquisition allows to perform the depth sensitive analysis and, thus, evaluate the defined layers of the multilayer structure. In this way, the deconvolution of overlapped broad peaks in Fig. 6 may be performed. Fig. 7 (a) shows the comparison of GIXRD and in-plane spectra with conventional $\theta / 2 \theta$ scan of sample 1.1 and reference position of the peaks from the database.

In addition to the feature of GIXRD analysis which allows to control X-ray penetration depth by incident angle, another advantage of in-plane XRD method is the acquisition of diffraction data from the lattice planes located along the normal to the surface, since the scattering vector $\mathbf{S}$ inclined parallel to the surface, in contrast to the out-of-plane type of scan. In asymmetric $\theta / 2 \theta$ scan, included GIXRD, S moves continuously with the detector. Therefore, different lattice planes normal to the $\mathbf{S}$ current position at each point of time will contribute to the resulting diffraction pattern. Fig. 7 (b) shows the comparison of in-plane XRD patterns for samples with CrN top layer (sample 1.1) and MoN top layer (sample 1.2). Fig. 7 (b) clearly shows similarity of $\mathrm{CrN}$ and $\mathrm{MoN}$ diffraction patterns, but successfully distinguishes the positions of diffraction peaks separately for $\mathrm{CrN}$ and MoN layers of the deposited multilayer films, which was not possible to achieve from integral spectra shown in Fig. 6 (a)-(c). The GIXRD and in-plane XRD data confirms the presence of cubic high-temperature $\gamma-\mathrm{Mo}_{2} \mathrm{~N}$ phase and stoichiometric phase of $\mathrm{CrN}$, which corresponds to the performed elemental analysis. Diffraction reflexes inherent to $\beta$ $\mathrm{Mo}_{2} \mathrm{~N}$ or $\beta-\mathrm{Cr}_{2} \mathrm{~N}$ phases were not detected.

The residual stress in PVD coatings appears mainly due to thermal and internal stresses. The thermal stress is caused by the difference in the temperature between coating and substrate during the cooling process after the deposition and by different thermal expansion coefficients of materials. Its contribution can increase for a system of several layers. The internal stress in PVD coatings occurs during deposition and its value depends on the deposition conditions, such as bias potential, chamber pressure and distance to the substrate, as well as on the stoichiometry and layers thickness in the coating [41], [42]-[44]. On the other hand, in multilayer systems the reduce of individual layer thickness leads to the increase of the interlayer interface volume which releases residual stress. Such effect was recently observed in the coatings with (111) preferential crystallographic orientation. At substructure level the grain size calculated from the XRD data decreases to $12 \mathrm{~nm}$ when the bilayer thickness reaches values of nanometre scale, and the microdeformation of the crystallites is $(0.4 \div 0.5) \%$. These values are slightly higher in the coatings of Series $1\left(\mathrm{U}_{\mathrm{b}}=-20 \mathrm{~V}\right)$. It may be explained by lower mobility of the deposited atoms, which leads to the lower probability of diffusion healing of growth defects [18], [44].

The additional EBSD analysis and corresponding software allowed to study the structure and evaluate the grain size, as well as to find correlations between these features and layer thickness. To show the results of EBSD analysis and to determine the position and shape of grains in the coatings a unique grains colour map was used (see Fig. 8). Colour separation is used to distinguish neighbour grains. The boundaries between the grains were reconstructed and are shown as polygons. It is clearly seen that the grains have oblong shape and are oriented in the direction to the films growth. The columnar structure and high degree of structuring are present in the deposited films which is typical for Arc-PVD method. 
Pole figures based on the data of EBSD analysis have shown the prevailing formation of fibre texture in [311] orientation for the samples of Series 1 deposited at $U_{b}=-20 \mathrm{~V}$, which is in agreement with the XRD results.

Used method also allows to perform the evaluation of grain size. The calculations clearly shown the persistent decrease of average grain size from $0.16 \mu \mathrm{m}$ (sample $1.1, \lambda=2.26 \mu \mathrm{m}$ ) to $0.11 \mu \mathrm{m}$ (sample $1.4, \lambda=0.25 \mu \mathrm{m}$ ). Th further study of the samples with thinner layers using EBSD was not possible due to the resolution limits of the discussed technique.

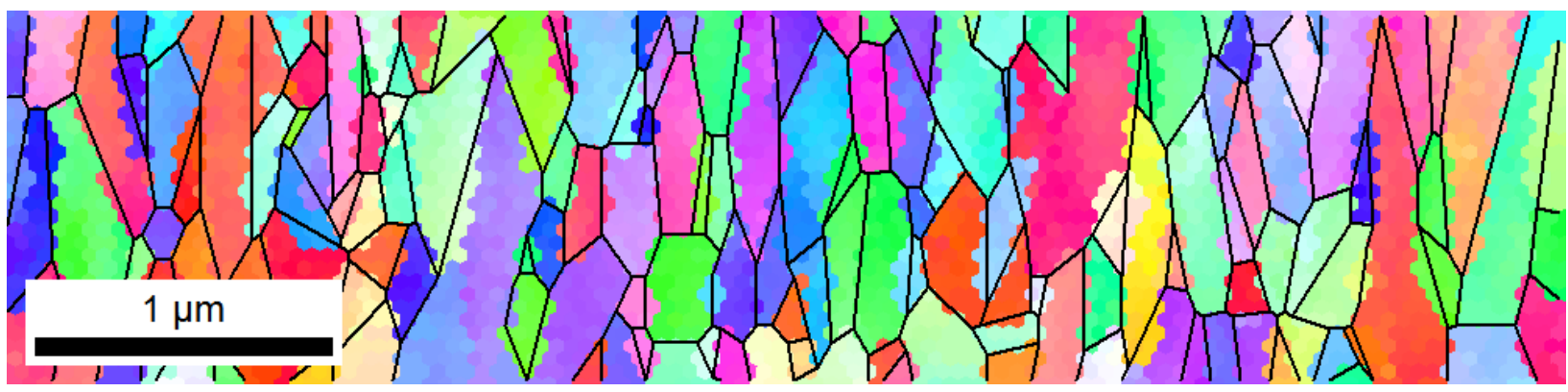

Figure 8 - EBSD results for CrN layer of sample 1.1: unique grains colour map with reconstructed boundaries.

The results of TEM and SAED analysis for Series $3\left(\mathrm{U}_{\mathrm{b}}=-300 \mathrm{~V}\right)$ showed a clear distribution of the layers (Fig. 9), with the thickness of the MoN layer about $36 \mathrm{~nm}$, which correlates with the result of RBS analysis (MoN layer thickness is about $37 \mathrm{~nm}$ ). The SAED method offers a high resolution and has much shorter wavelengths compared to conventional X-rays. On the other hand, the structural factors of electron diffraction are up to 10,000 times higher than for diffraction of X-rays and, thus, provides much higher diffraction beam intensity. Due to the shorter wavelength, the diffraction angles for SAED are only a few degrees, which results in a greatly reduced angular resolution. Because of this, the accuracy of determining the interplanar distances is lower than for XRD (about 1-3\%). The higher spatial resolution of SAED makes it possible to probe an area of no more than 2-5 microns in diameter and does not give a complete picture.

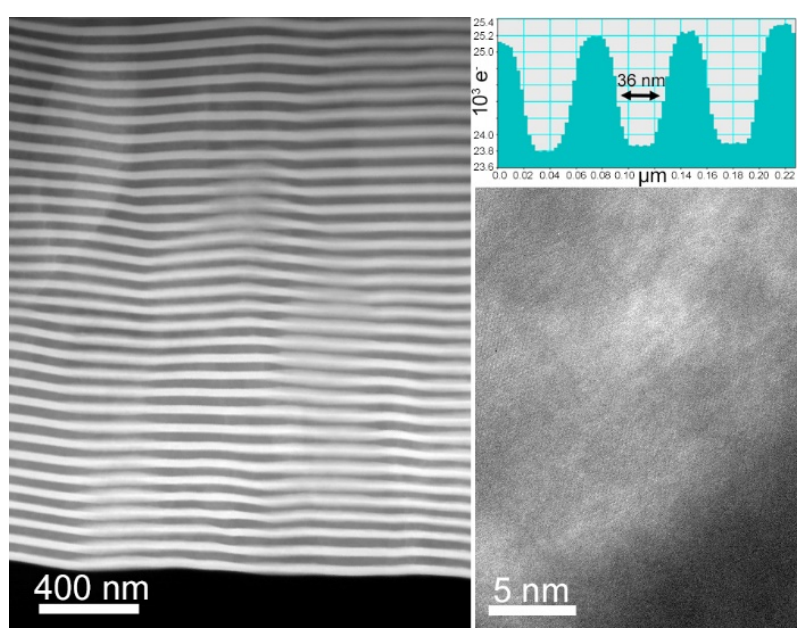

(a)

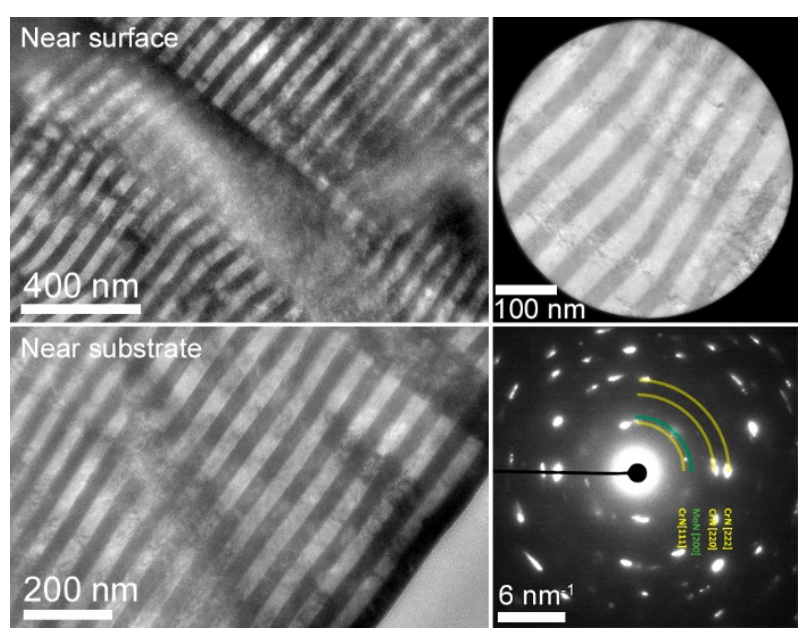

(b)

Figure 9 - TEM and HR-TEM images ((a) and (b, left) and SAED analysis (b, right) for sample 3.6.

The SAED results presented in Fig. 9 (b, right) show the formation of two main characteristic cubic phases $\mathrm{CrN}$ and $\gamma-\mathrm{Mo}_{2} \mathrm{~N}$, which coincides with the conclusions of of the preliminary XRD analysis. The SAED pattern demonstrates the presence of several crystallite orientations for both 
cubic structures in polynanocrystalline sample: [111], [200], [220], [222], [311] and others. The relatively high discreteness and thin width of the lines of the diffraction patterns indicate the presence of sufficiently large crystallites and the probable superposition of their crystallographic directions [45]. The very similar cubic structure of $\mathrm{CrN}$ and $\gamma-\mathrm{Mo}_{2} \mathrm{~N}$ phases in a couple with limited angle resolution by TEM-SAED may not allow to define separately diffractions from $\mathrm{CrN}$ and MoN layers of studied sample, but could help to estimate average interplanar distances and, thus, lattice parameters as for "solid solution" $(\mathrm{Cr}, \mathrm{Mo}) \mathrm{N}$. The calculated interplanar distances were 2.24, 1.88, 1.37, 1.18 and $0.87 \AA$ for (111), (200), (220), (222) and (311) planes respectively, which results in lattice parameter in direction parallel to the films surface $a_{\|}=$ (3.75-4.08) $\AA$. Decreased value of $\mathrm{a}_{\|}$, in comparison to stress-free values from database for $\mathrm{CrN}$ $(4.14 \AA)$ and $\gamma-\mathrm{Mo}_{2} \mathrm{~N}(4.163 \AA)$, clearly demonstrates the presence of compressive stress in deposited films, which vector lies parallel to the coatings surface. The limited implementation of thin section for further determination of nanograins size related to the presence of internal stresses should be noted [46], [47].

Figure 10 represents the results of TEM-EDS analysis performed on sample 3.6. Figure 10(a) demonstrates almost equal concentration of $\mathrm{Cr}$ and Mo elements (41.1 and 42.0 at.\% respectively) which confirms results of previous SEM-EDS and RBS analysis. Concentration of Nitrogen was shown on the level up to 16.9 at.\%, but it was already mentioned the low reliability of light elements concentration measurement by EDS technique. Figure 10(b) shows depth profile concentration of the considered multilayer sample and layers exhibit good uniformity and stability. In the figure the depth profile is also combined with the part of real TEM cross-section image of the same area. Sharp interface between the layers and good contrast are confirmed by TEM technique for the thinnest samples, which was difficult using SEM.
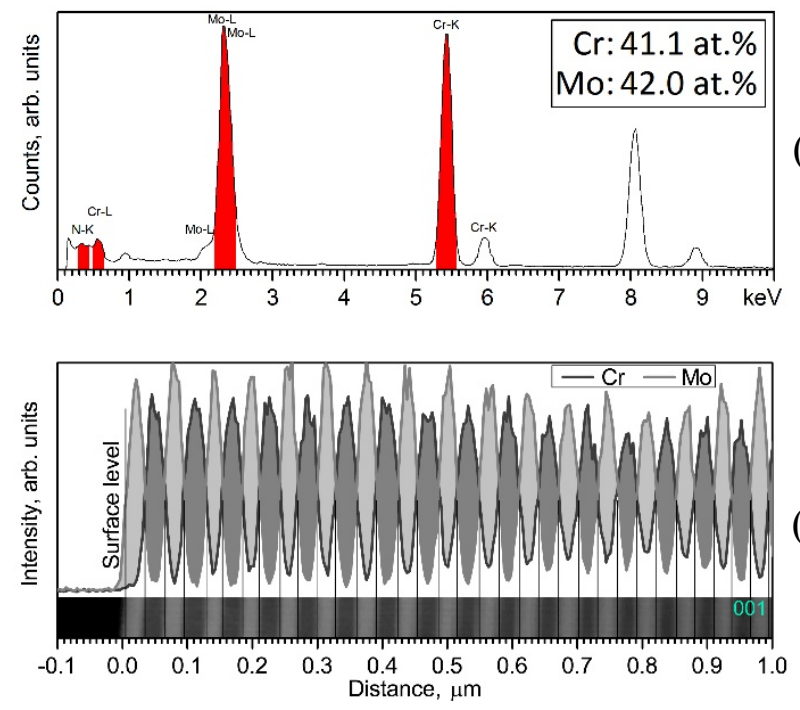

Figure 10 - Results of TEM-EDS analysis for sample 3.6: (a) TEM-EDS spectrum, elemental composition; (b) $\mathrm{Cr}$ and Mo elemental depth profile with corresponded part of TEM cross-section image.

\subsection{Physical and Mechanical Properties}

The results of mechanical properties evaluation are shown in Fig. 11. The highest values of measured hardness were demonstrated by the films deposited at the lowest absolute value of the negative bias voltage $\mathrm{U}_{\mathrm{b}}=-20 \mathrm{~V}$ (Series 1). This regime also provides higher nitrogen 
concentration in the films. For the multilayer samples of Serie 1 the hardness growth is observed while the individual layer thickness decreases. This phenomenon may happen due to the HallPetch strengthening mechanism [52], where the dislocations appear at the interfaces repel the cracks propagation and, in this way, the hardness enhancement occurs. The results presented in this work are in a good agreement with the similar results for nanoscale multilayer coatings, where the mechanical properties improve when the bilayer period decreases [51-53].

As seen from Fig. 11 (a) the hardness values for the samples of Series 1 are in a range of 25$39 \mathrm{GPa}$, where the hardness is significantly increased where the individual layer thickness of films is $60 \mathrm{~nm}$ or thinner. Furthermore, it should be noted that in some coatings (samples 1.41.6) the hardness had values above $40 \mathrm{GPa}$, up to $42.3 \mathrm{GPa}$, which means they belong to superhard class.

For the higher absolute value of bias voltage $U_{b}=-150 \mathrm{~V}$ such kind of tendency of hardness increase is observed only for the individual layer thickness up to 40-50 nm and then, for thinner layers, the hardness decreases. In correspondence to the XRD structural analysis data one may assume that the reason of the hardness drop is the loss of barrier properties due to the intensification of the high-energy particles mixing process in a near-interface interlayer zone. In relatively thin layers of coatings (tens of nanometres) it leads to the formation of large volume of mixed regions with $(\mathrm{Cr}, \mathrm{Mo}) \mathrm{N}$ solid solution state $[46,45]$ and, thereby, to the decrease of hardness values.

For $\mathrm{U}_{\mathrm{b}}=-300 \mathrm{~V}$ the mentioned-above relation of hardness drop remains even for thicker layers of the films (see Fig. 11 (a)m blue line).

The highest hardness of coatings is achieved in the presence of $\mathrm{CrN}$ phases with a cubic lattice in the layers and a relatively small region of homogeneity in composition.

For the further characterisation of mechanical and, thus, protective properties the ratio of hardness and Young's modulus is introduced in the form of $\mathrm{H} / \mathrm{E}$ parameter [11,20,42,52,59-62]. In Fig. 11 (b) the area is divided into two zones along the line $\mathrm{H} / \mathrm{E}=0.1$. As it shown three samples are in the region $\mathrm{H} / \mathrm{E}>0.1$ (plasticity zone), which characterizes them as coatings with increased wear resistance. The growth of the considered mechanical parameters such as hardness, Young's modulus and H/E ratio with decrease of bilayer thickness of the considered multilayer CrN/MoN coatings of Series 1 is evident. Such tendency can be associated with a corresponding decrease in the grain size, which leads to an increase of the interphase boundaries and an enhancement of the Hall-Petch effect, preventing the movement of dislocations. In this case, a stronger increase in hardness does not occur due to the likely occurrence of a coherent voltage, described in the Ghana model [63]. 


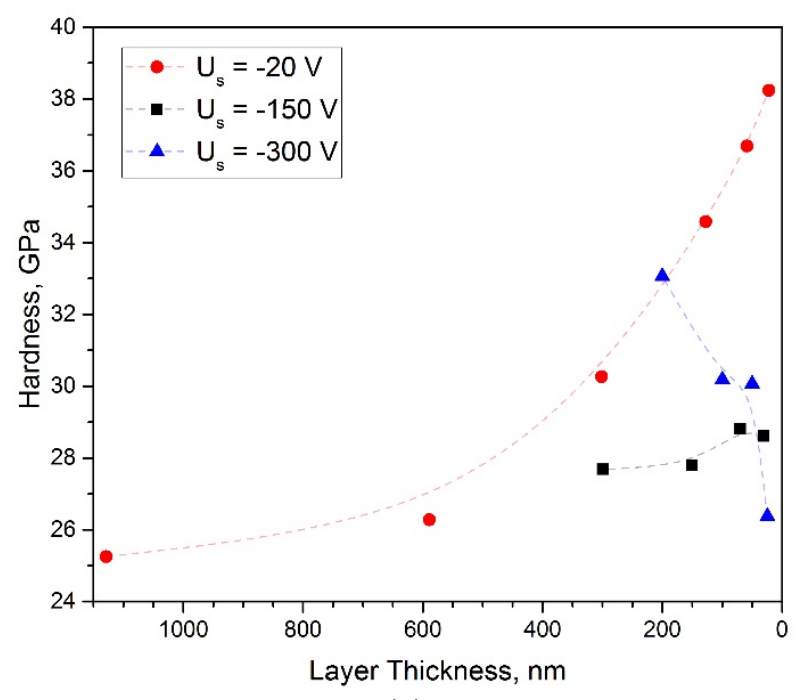

(a)

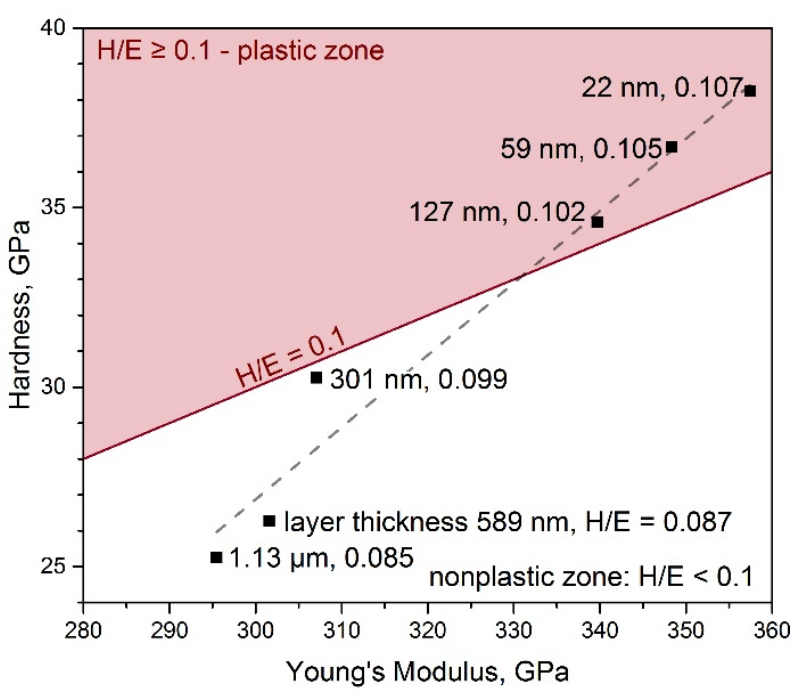

(b)

Figure 11 - Results of mechanical tests: (a) - Hardness measurements fir three series of samples; (b) Characterization of plasticity properties of Series 1 by H/E ratio.

\subsection{Tribology and Wear}

The results of tribological tests of the coatings deposited at different nitrogen pressures are given in Table 2.

Table 2 - Tribological properties of $\mathrm{CrN} / \mathrm{MoN}$ coatings obtained at $\mathrm{U}_{\mathrm{b}}=-150 \mathrm{~V}$ and different nitrogen pressures.

\begin{tabular}{|c|c|c|c|c|c|c|}
\hline \multirow{2}{*}{$\begin{array}{l}\text { Sample } \\
\text { number }\end{array}$} & \multirow{2}{*}{$\begin{array}{l}\text { Nitrogen } \\
\text { pressure } \mathrm{p}_{\mathrm{N}}, \\
\mathrm{Pa}\end{array}$} & \multicolumn{2}{|c|}{ Friction coefficient, $\mu$} & \multicolumn{2}{|c|}{ Wear rate $v, \mathrm{~mm}^{3} \times \mathrm{N}^{-1} \times \mathrm{m}^{-1}$} & \multirow{2}{*}{$\begin{array}{l}\mathrm{R}_{\mathrm{a}} \\
\mu \mathrm{m}\end{array}$} \\
\hline & & Initial & During experimen & $\begin{array}{l}\text { Counterbody } \\
\left(\mathrm{Al}_{2} \mathrm{O}_{3}\right)\end{array}$ & Coating & \\
\hline 2.4 & 0.4 & 0.535 & 0.579 & $0.86 \times 10^{-7}$ & $6.36 \times 10^{-7}$ & 0.28 \\
\hline 2.7 & 0.09 & 0.381 & 0.586 & $0.25 \times 10^{-7}$ & $13.45 \times 10^{-7}$ & 0.47 \\
\hline
\end{tabular}

At low pressure $\mathrm{p}_{\mathrm{N}}=0.09 \mathrm{~Pa}$ when the formation of different crystal lattices and phases occurs in the $\mathrm{MoN}$ and $\mathrm{CrN}$ layers the increase of brittleness and higher wear of the coatings are observed, in a contrast to the counterbody. With the increase of nitrogen pressure $\mathrm{p}_{\mathrm{N}}$ to $0.4 \mathrm{~Pa}$ and the appearance of cubic lattices incorporation in $(111) \mathrm{CrN} /(111) \gamma-\mathrm{Mo}_{2} \mathrm{~N}$ layers, the wear resistance increases up to 2 times.

Fig. 12 shows the surface of the coating after the interaction with the counterbody, the wear track and the resulting profilograms. The comparison of the tribological tests results clearly demonstrates the adhesive wear mechanism at high pressure $\mathrm{p}_{\mathrm{N}}=0.4 \mathrm{~Pa}$. It is characterised by the transfer of material from one surface to another one and by homogeneous wear of coating with symmetrical shape of wear track profile similar to the counterbody shape (Fig. 12 (c). In this case, according to the previous works [61], [62], [63,67], the amount of transferred material depends on the adhesive bonds strength, which is directly connected with the electronic structure of the $\mathrm{Al}_{2} \mathrm{O}_{3}$ counterbody and the MoN/CrN coating, and their compatibility to form solid solutions or intermetallic compounds with each other $[47,68]$.

For the coatings deposited at lower nitrogen pressure $\mathrm{p}_{\mathrm{N}}=0.09 \mathrm{~Pa}$ the mechanism of abrasive wear was considered. It may appear both due to the coatings deposition process and due to the 
different types of crystal lattices formed in nitride layers. The self-destruction process is quite homogeneous, which is characterised by the absence of significant breaks and cracks at all stages of wear. The enhancement of adhesion is possible due to microcracks, which appear mainly near to the surface, and, in turn, interlayer interfaces may change significantly the direction of the initial crack propagation when it penetrates deep into the coating. Consequently, multilayer and multicomponent structures improve the mechanical properties of the surface, because interfaces and boundaries block the propagation of dislocations and the deformations locate in near to the surface zone.

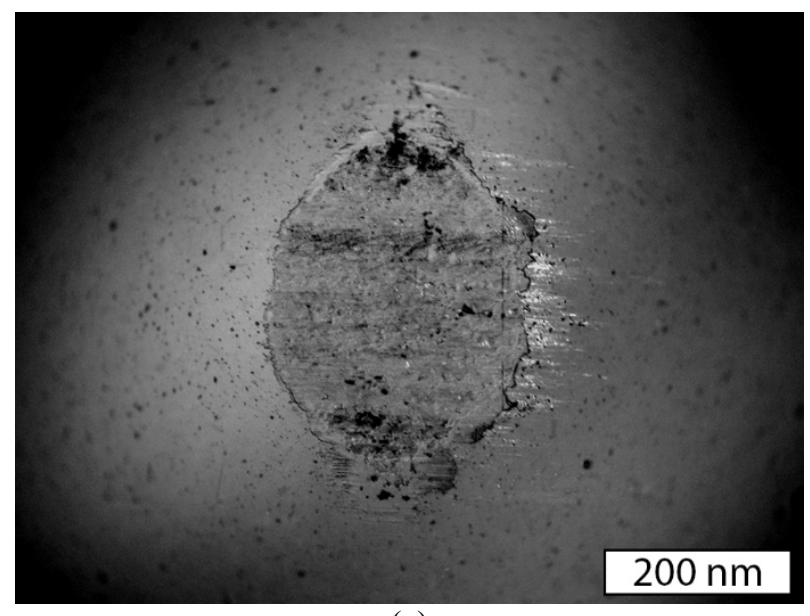

(a)

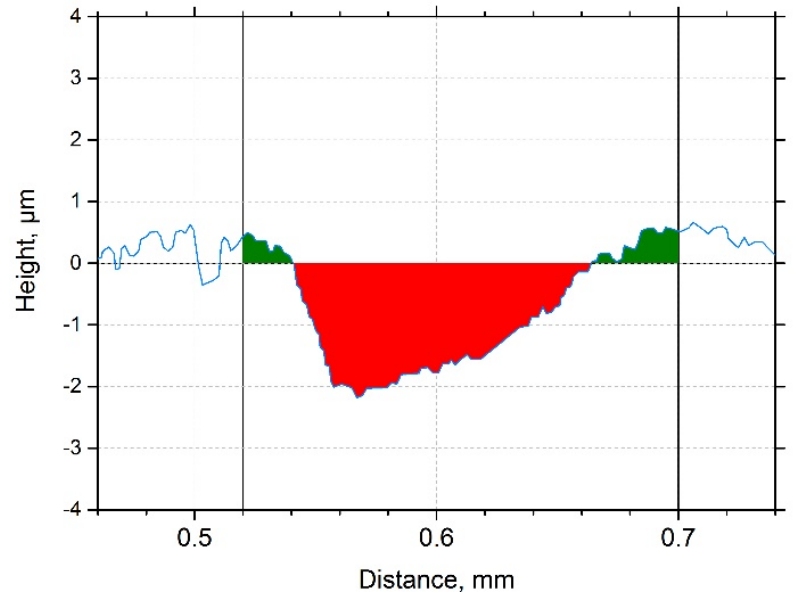

(c)

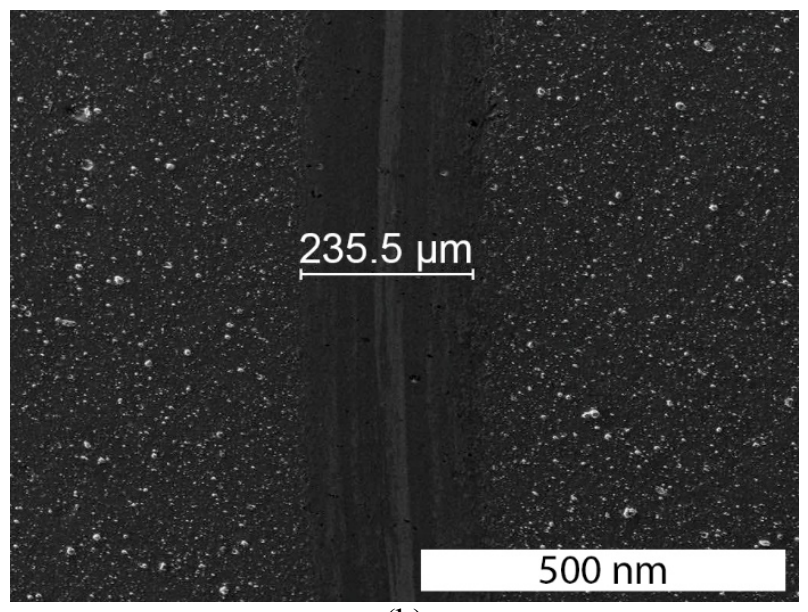

(b)

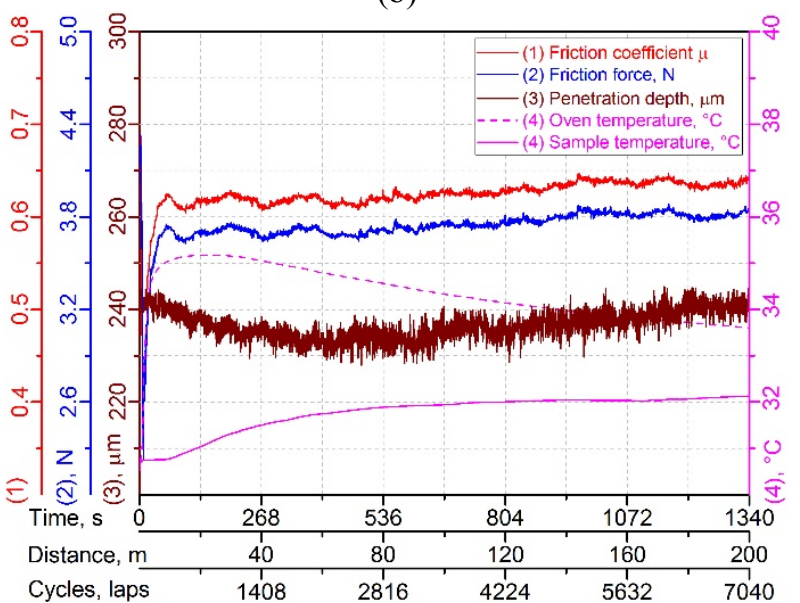

(d)

Figure 12 - Images of ball crater in $\mathrm{CrN} / \mathrm{MoN}$ multilayer coating (a), wear track (b), profilogram of dynamical test (c) and records of tribological test with spherical $\mathrm{Al}_{2} \mathrm{O}_{3}$ counterbody for sample 2.4 (d).

The results of tribological tests of the coating deposited at high pressure $\mathrm{p}_{\mathrm{N}}=0.4 \mathrm{~Pa}$ and bias voltage $U_{b}=-150 \mathrm{~V}$ are presented in Fig. $12(\mathrm{~d})$. It is possible to estimate the wear rate relatively to the volume of the wear material. A higher rate of wear indicates that the coating more effectively resists destruction caused by plastic deformation or microcracks during penetration. The wear rate increases with decreasing of bilayer thickness [47,68-70].

As a result, the gradual increase in the friction coefficient (0.62-0.65) respectively to the growth of the applied load (3.65-3.82 N) is observed. The maximum increase in the coefficient is reached at the end of the path $(200 \mathrm{~m})$ with the penetration of the counterbody into the coating. With the increase of the depth, the small transfer of material from the coating to the counterbody is observed, therefore, the adhesion mechanism of wear occurs. 


\section{Conclusions}

Multilayer nanostructured MoN/CrN coatings deposited by vacuum-arc evaporation of the cathodes in nitrogen atmosphere were studied in the paper. Elemental analysis performed by nuclear physical methods (RBS, SIMS, EDS) showed good quality of the coatings, and the clear separation of the CrN and MoN layers was observed. SEM, SIMS and HRTEM analyses confirm well-defined multilayer structures and show the compositional and structural assembly of the films. All deposited coatings demonstrate the columnar growth with high degree of structuring. The increase of the absolute value of negative bias voltage from $-20 \mathrm{~V}$ to $-300 \mathrm{~V}$ leads to the changes in the preferential crystallographic orientation of two main cubic phases $\mathrm{CrN}$ and $\gamma-\mathrm{Mo}_{2} \mathrm{~N}$ presented in films from (311) when $\mathrm{U}_{\mathrm{b}}=-20 \mathrm{~V}$ to more stable (111) crystal orientation when $U_{b}=-150 \mathrm{~V}$ and then $(200)$ at $U_{b}=-300 \mathrm{~V}$. When the nitrogen pressure in chamber decreases the formation of $\beta-\mathrm{Cr}_{2} \mathrm{~N}$ phase begins, which causes the deterioration of tribological properties of multilayer system. The decrease of individual layer thickness of the coatings leads to the decrease of crystallite size to $12 \mathrm{~nm}$, which is clearly seen from the broadening of diffraction peaks on XRD spectra. Additional GIXRD and in-plane analyses confirmed the presence of two main phases $\gamma-\mathrm{Mo}_{2} \mathrm{~N}$ and $\mathrm{CrN}$ with cubic crystal lattice ( $\mathrm{NaCl}$ type). The equal interplanar distances in the contacting layers of chromium and molybdenum nitrides indicates an interrelated growth of these two structures, which corresponds to the equiatomic Cr/Mo ratio. The depth profiles from the RBS analysis confirm the homogeneity of the layers and the good quality of the coatings. Tribological tests of coatings have shown a significant effect of chamber pressure on wear resistance: coatings deposited at high nitrogen pressure demonstrates better durability and, hence, longer lifetime. The highest values of hardness up to $42.3 \mathrm{GPa}$ were registered in the coatings of series deposited at the lowest absolute value of negative voltage $\mathrm{U}_{\mathrm{b}}=-20 \mathrm{~V}$ in range of individual layer thickness $60-20 \mathrm{~nm}$. The growth of the hardness with the increase of the layer thickness to $20 \mathrm{~nm}$ occurs mainly due to the Hall-Petch strengthening mechanism.

The approach to use multilayer architecture with control of individual layer thickness and control of deposition parameters, such as bias voltage or working nitrogen pressure, was approved as an effective method of transition metals nitride films fabrication.

\section{Acknowledgements}

This work was supported by the state budget programs of Ukraine [grant numbers 0116U002621, 0115U000682, 0116U006816], the Foundation of Science and Technology (FCT) of Portugal [grant numbers UID/NAN/50024/2013, NORTE-01-0145-FEDER-022096, SFRH/BD/129614/2017] and Network of Extreme Conditions Laboratories (NECL).

\section{References}

[1] J. An, Q.Y. Zhang, Structure, hardness and tribological properties of nanolayered TiN/TaN multilayer coatings, Mater. Charact. 58 (2007) 439-446.

[2] T. An, M. Wen, L.L. Wang, C.Q. Hu, H.W. Tian, W.T. Zheng, Structures, mechanical properties and thermal stability of $\mathrm{TiN} / \mathrm{SiN}_{\mathrm{x}}$ multilayer coatings deposited by magnetron sputtering, J. Alloys Compd. 486 (2009) 515-520. 
[3] V.M. Beresnev, O. V. Bondar, B.O. Postolnyi, M.O. Lisovenko, G. Abadias, P. Chartier, D.A. Kolesnikov, V.N. Borisyuk, B.A. Mukushev, B.R. Zhollybekov, A.A. Andreev, Comparison of tribological characteristics of nanostructured TiN, MoN, and TiN/MoN Arc-PVD coatings, J. Frict. Wear. 35 (2014) 374-382.

[4] O. V. Bondar, B.A. Postol'nyi, V.M. Beresnev, G. Abadias, P. Chartier, O. V. Sobol, D.A. Kolesnikov, F.F. Komarov, M.O. Lisovenko, A.A. Andreev, Composition, structure and tribotechnical properties of TiN, MoN single-layer and TiN/MoN multilayer coatings, J. Superhard Mater. 37 (2015) 27-38.

[5] J.C. Caicedo, C. Amaya, L. Yate, O. Nos, M.E. Gomez, P. Prieto, Hard coating performance enhancement by using [Ti/TiN]n, [Zr/ZrN]n and [TiN/ZrN]n multilayer system, Mater. Sci. Eng. B. 171 (2010) 56-61.

[6] P. Eklund, M. Beckers, U. Jansson, H. Högberg, L. Hultman, The $M_{n+1} A X_{n}$ phases: Materials science and thin-film processing, Thin Solid Films. 518 (2010) 1851-1878.

[7] F.F. Klimashin, N. Koutná, H. Euchner, D. Holec, P.H. Mayrhofer, The impact of nitrogen content and vacancies on structure and mechanical properties of Mo-N thin films, J. Appl. Phys. 120 (2016) 185301.

[8] G. Fox-Rabinovich, A. Kovalev, M.H. Aguirre, K. Yamamoto, S. Veldhuis, I. Gershman, A. Rashkovskiy, J.L. Endrino, B. Beake, G. Dosbaeva, D. Wainstein, J. Yuan, J.W. Bunting, Evolution of self-organization in nano-structured PVD coatings under extreme tribological conditions, Appl. Surf. Sci. 297 (2014) 22-32.

[9] A. Gilewicz, B. Warcholinski, Tribological properties of $\mathrm{CrCN} / \mathrm{CrN}$ multilayer coatings, Tribol. Int. 80 (2014) 34-40.

[10] U. Helmersson, S. Todorova, S.A. Barnett, J. -E. Sundgren, L.C. Markert, J.E. Greene, Growth of single-crystal TiN/VN strained-layer superlattices with extremely high mechanical hardness, J. Appl. Phys. 62 (1987) 481-484.

[11] V.I. Ivashchenko, S. Veprek, P.E.A. Turchi, V.I. Shevchenko, First-principles study of TiN/SiC/TiN interfaces in superhard nanocomposites, Phys. Rev. B. 86 (2012) 14110.

[12] A.D. Pogrebnjak, A. V Pshyk, V.M. Beresnev, B.R. Zhollybekov, Protection of specimens against friction and wear using titanium-based multicomponent nanocomposite coatings: A review, J. Frict. Wear. 35 (2014) 55-66.

[13] L.G. Parratt, Surface Studies of Solids by Total Reflection of X-Rays, Phys. Rev. 95 (1954) 359-369.

[14] A. Medvedeva, J. Bergström, S. Gunnarsson, J. Andersson, High-temperature properties and microstructural stability of hot-work tool steels, Mater. Sci. Eng. A. 523 (2009) 3946.

[15] T. Teppernegg, C. Czettl, C. Michotte, C. Mitterer, Arc evaporated Ti-Al-N/Cr-Al-N multilayer coating systems for cutting applications, Int. J. Refract. Met. Hard Mater. 72 (2018) 83-88.

[16] C.M. Koller, A. Kirnbauer, S. Kolozsvári, J. Ramm, P.H. Mayrhofer, Impact of morphology and phase composition on mechanical properties of $\alpha$-structured $(\mathrm{Cr}, \mathrm{Al}) 2 \mathrm{O}$ 3 /(Al,Cr,X) 2 O 3 multilayers, Scr. Mater. 146 (2018) 208-212.

[17] Z. Lei, Q. Zhang, X. Zhu, D. Ma, F. Ma, Z. Song, Y.Q. Fu, Corrosion performance of 
$\mathrm{ZrN} / \mathrm{ZrO} 2$ multilayer coatings deposited on 304 stainless steel using multi-arc ion plating, Appl. Surf. Sci. 431 (2018) 170-176.

[18] A.D. Pogrebnjak, D. Eyidi, G. Abadias, O.V. Bondar, V.M. Beresnev, O.V. Sobol, Structure and properties of arc evaporated nanoscale TiN/MoN multilayered systems, Int. J. Refract. Met. Hard Mater. 48 (2015) 222-228.

[19] R.A. Koshy, M.E. Graham, L.D. Marks, Synthesis and characterization of CrN/Mo ${ }_{2} \mathrm{~N}$ multilayers and phases of Molybdenum nitride, Surf. Coatings Technol. 202 (2007) 11231128.

[20] A.K. Kuleshov, V. V. Uglov, V. V. Chayevski, V.M. Anishchik, Properties of coatings based on $\mathrm{Cr}$, Ti, and Mo nitrides with embedded metals deposited on cutting tools, J. Frict. Wear. 32 (2011) 192-198.

[21] M. Nordin, M. Larsson, S. Hogmark, Mechanical and tribological properties of multilayered PVD TiN/CrN, TiN/MoN, TiN/NbN and TiN/TaN coatings on cemented carbide, Surf. Coatings Technol. 106 (1998) 234-241.

[22] R.A. Koshy, M.E. Graham, L.D. Marks, Temperature activated self-lubrication in $\mathrm{CrN} / \mathrm{Mo}_{2} \mathrm{~N}$ nanolayer coatings, Surf. Coatings Technol. 204 (2010) 1359-1365.

[23] B. Han, Z. Wang, N. Devi, K.K. Kondamareddy, Z. Wang, N. Li, W. Zuo, D. Fu, C. Liu, RBS Depth Profiling Analysis of (Ti, Al)N/MoN and CrN/MoN Multilayers, Nanoscale Res. Lett. 12 (2017) 161.

[24] G. Abadias, S. Dub, R. Shmegera, Nanoindentation hardness and structure of ion beam sputtered TiN, W and TiN/W multilayer hard coatings, Surf. Coatings Technol. 200 (2006) 6538-6543.

[25] M. Stueber, H. Holleck, H. Leiste, K. Seemann, S. Ulrich, C. Ziebert, Concepts for the design of advanced nanoscale PVD multilayer protective thin films, J. Alloys Compd. 483 (2009) 321-333.

[26] A. Pogrebnjak, V. Ivashchenko, O. Bondar, V. Beresnev, O. Sobol, K. Załęski, S. Jurga, E. Coy, P. Konarski, B. Postolnyi, Multilayered vacuum-arc nanocomposite TiN/ZrN coatings before and after annealing: Structure, properties, first-principles calculations, Mater. Charact. 134 (2017) 55-63.

[27] F. Fernandes, M. Danek, T. Polcar, A. Cavaleiro, Tribological and cutting performance of TiAlCrN films with different $\mathrm{Cr}$ contents deposited with multilayered structure, Tribol. Int. 119 (2018) 345-353.

[28] P. Xue, L. Yang, D. Diao, Nanocrystalline/amorphous biphase enhanced mechanical properties in multilayer carbon films, Surf. Coatings Technol. 334 (2018) 1-6.

[29] B. Navinšek, P. Panjan, I. Milošev, Industrial applications of CrN (PVD) coatings, deposited at high and low temperatures, Surf. Coatings Technol. 97 (1997) 182-191.

[30] A.D. Pogrebnjak, O.M. Ivasishin, V.M. Beresnev, Arc-Evaporated Nanoscale Multilayer Nitride-Based Coatings for Protection Against Wear, Corrosion, and Oxidation, Usp. Fiz. Met. 17 (2016) 1-28.

[31] A. Gilewicz, B. Warcholinski, Deposition and characterisation of $\mathrm{Mo}_{2} \mathrm{~N} / \mathrm{CrN}$ multilayer coatings prepared by cathodic arc evaporation, Surf. Coatings Technol. 279 (2015) 126133. 
[32] I. Jauberteau, A. Bessaudou, R. Mayet, J. Cornette, J. Jauberteau, P. Carles, T. MerleMéjean, Molybdenum Nitride Films: Crystal Structures, Synthesis, Mechanical, Electrical and Some Other Properties, Coatings. 5 (2015) 656-687.

[33] B.O. Postolnyi, V.M. Beresnev, G. Abadias, O.V. Bondar, L. Rebouta, J.P. Araujo, A.D. Pogrebnjak, Multilayer design of CrN/MoN protective coatings for enhanced hardness and toughness, J. Alloys Compd. 725 (2017) 1188-1198.

[34] F. Ma, J. Li, Z. Zeng, Y. Gao, Structural, mechanical and tribocorrosion behaviour in artificial seawater of CrN/AlN nano-multilayer coatings on F690 steel substrates, Appl. Surf. Sci. 428 (2018) 404-414.

[35] Z.H. Xie, M. Hoffman, P. Munroe, R. Singh, A. Bendavid, P.J. Martin, Microstructural response of TiN monolithic and multilayer coatings during microscratch testing, J. Mater. Res. 22 (2007) 2312-2318.

[36] M.I. Yousaf, V.O. Pelenovich, B. Yang, C.S. Liu, D.J. Fu, Effect of bilayer period on structural and mechanical properties of nanocomposite TiAlN/MoN multilayer films synthesized by cathodic arc ion-plating, Surf. Coatings Technol. 282 (2015) 94-102.

[37] M.K. Samani, X.Z. Ding, N. Khosravian, B. Amin-Ahmadi, Y. Yi, G. Chen, E.C. Neyts, A. Bogaerts, B.K. Tay, Thermal conductivity of titanium nitride/titanium aluminum nitride multilayer coatings deposited by lateral rotating cathode arc, Thin Solid Films. 578 (2015) 133-138.

[38] L.A. Rocha, E. Ariza, J. Ferreira, F. Vaz, E. Ribeiro, L. Rebouta, E. Alves, A.R. Ramos, P. Goudeau, J.P. Rivière, Structural and corrosion behaviour of stoichiometric and substoichiometric TiN thin films, Surf. Coatings Technol. 180-181 (2004) 158-163.

[39] P.C. Yashar, W.D. Sproul, Nanometer scale multilayered hard coatings, Vacuum. 55 (1999) 179-190.

[40] H. Hazar, Characterization of MoN coatings for pistons in a diesel engine, Mater. Des. 31 (2010) 624-627.

[41] S.H. Yao, Y.L. Su, The tribological potential of $\mathrm{CrN}$ and $\mathrm{Cr}(\mathrm{C}, \mathrm{N})$ deposited by multi-arc PVD process, Wear. 212 (1997) 85-94.

[42] L. Shen, N. Wang, Effect of Nitrogen Pressure on the Structure of Cr-N, Ta-N, Mo-N, and W-N Nanocrystals Synthesized by Arc Discharge, J. Nanomater. 2011 (2011) 1-5.

[43] X.M. Xu, J. Wang, J. An, Y. Zhao, Q.Y. Zhang, Effect of modulation structure on the growth behavior and mechanical properties of TiN/ZrN multilayers, Surf. Coatings Technol. 201 (2007) 5582-5586.

[44] L. Rogström, L.J.S. Johnson, M.P. Johansson, M. Ahlgren, L. Hultman, M. Odén, Thermal stability and mechanical properties of arc evaporated ZrN/ZrAlN multilayers, Thin Solid Films. 519 (2010) 694-699.

[45] R. R Development Core Team, Computational Many-Particle Physics, Springer Berlin Heidelberg, Berlin, Heidelberg, 2008.

[46] B. Han, V.O. Pelenovich, M.I. Yousaf, S.J. Yan, W. Wang, S.Y. Zhou, B. Yang, Z.W. Ai, C.S. Liu, D.J. Fu, Properties of $\mathrm{CrN} / \mathrm{Mo}_{2} \mathrm{~N}$ nano-multilayer films synthesized by multicathodic arc ion plating system, Thin Solid Films. 619 (2016) 160-165. 
[47] Q. Wang, F. Zhou, J. Yan, Evaluating mechanical properties and crack resistance of CrN, CrTiN, CrAlN and CrTiAlN coatings by nanoindentation and scratch tests, Surf. Coatings Technol. 285 (2016) 203-213.

[48] C. Sarioglu, U. Demirler, M.K. Kazmanli, M. Urgen, Measurement of residual stresses by $\mathrm{X}$-ray diffraction techniques in $\mathrm{MoN}$ and $\mathrm{Mo}_{2} \mathrm{~N}$ coatings deposited by arc PVD on highspeed steel substrate, Surf. Coatings Technol. 190 (2005) 238-243.

[49] H. Högberg, L. Hultman, J. Emmerlich, T. Joelsson, P. Eklund, J.M. Molina-Aldareguia, J.-P. Palmquist, O. Wilhelmsson, U. Jansson, Growth and characterization of MAX-phase thin films, Surf. Coatings Technol. 193 (2005) 6-10.

[50] H. Söderberg, M. Odén, J.M. Molina-Aldareguia, L. Hultman, Nanostructure formation during deposition of $\mathrm{TiNSiN}_{\mathrm{x}}$ nanomultilayer films by reactive dual magnetron sputtering, J. Appl. Phys. 97 (2005) 114327.

[51] Q. Yang, L.R. Zhao, R. McKellar, P.C. Patnaik, Microstructure and mechanical properties of multi-constituent superlattice coatings, Vacuum. 81 (2006) 101-105.

[52] A. Monshi, M.R. Foroughi, M.R. Monshi, Modified Scherrer Equation to Estimate More Accurately Nano-Crystallite Size Using XRD, World J. Nano Sci. Eng. 2 (2012) 154-160.

[53] S.P. Pemmasani, K. Valleti, R.C. Gundakaram, K. V. Rajulapati, R. Mantripragada, S. Koppoju, S. V Joshi, Effect of microstructure and phase constitution on mechanical properties of $\mathrm{Ti}_{1-\mathrm{x}} \mathrm{Al}_{\mathrm{x}} \mathrm{N}$ coatings, Appl. Surf. Sci. 313 (2014) 936-946.

[54] W. Chen, Y. Lin, J. Zheng, S. Zhang, S. Liu, S.C. Kwon, Preparation and characterization of CrAlN/TiAlSiN nano-multilayers by cathodic vacuum arc, Surf. Coatings Technol. 265 (2015) 205-211.

[55] C.J. Tavares, L. Rebouta, B. Almeida, J. Bessa e Sousa, Structural characterization of multilayered sputtered TiN/ZrN coatings, Surf. Coatings Technol. 100-101 (1998) 65-71.

[56] D. Hu, R.R. Botten, Phase transformations in some TiAl-based alloys, Intermetallics. 10 (2002) 701-715.

[57] F. Wu, S. Tien, J. Duh, J. Lee, Microstructure evaluation and mechanical properties of nanolayered chromium nitride/tungsten nitride coating, J. Electron. Mater. 34 (2005) $1533-1537$.

[58] P.H. Mayrhofer, C. Mitterer, L. Hultman, H. Clemens, Microstructural design of hard coatings, Prog. Mater. Sci. 51 (2006) 1032-1114.

[59] J.C. Caicedo, G. Zambrano, W. Aperador, L. Escobar-Alarcon, E. Camps, Mechanical and electrochemical characterization of vanadium nitride (VN) thin films, Appl. Surf. Sci. 258 (2011) 312-320.

[60] T. Polcar, A. Cavaleiro, High-temperature tribological properties of CrAlN, CrAlSiN and AlCrSiN coatings, Surf. Coatings Technol. 206 (2011) 1244-1251.

[61] M. Zhu, F. Xuan, J. Chen, Influence of microstructure and microdefects on long-term fatigue behavior of a Cr-Mo-V steel, Mater. Sci. Eng. A. 546 (2012) 90-96.

[62] J. Musil, Hard nanocomposite coatings: Thermal stability, oxidation resistance and toughness, Surf. Coatings Technol. 207 (2012) 50-65. 
[63] W. Gulbiński, T. Suszko, Thin films of $\mathrm{Mo}_{2} \mathrm{~N} / \mathrm{Ag}$ nanocomposite - the structure, mechanical and tribological properties, Surf. Coatings Technol. 201 (2006) 1469-1476.

[64] A.D. Pogrebnjak, A.A. Bagdasaryan, I. V Yakushchenko, V.M. Beresnev, The structure and properties of high-entropy alloys and nitride coatings based on them, Russ. Chem. Rev. 83 (2014) 1027-1061.

[65] M.A. Lieberman, A.J. Lichtenberg, Principles of Plasma Discharges and Materials Processing, Wiley-Inte, John Wiley \& Sons, Inc., Hoboken, NJ, USA, 2005.

[66] Y. You, S.N. Jung, Optimum active twist input scenario for performance improvement and vibration reduction of a helicopter rotor, Aerosp. Sci. Technol. 63 (2017) 18-32.

[67] S. Hogmark, S. Jacobson, M. Larsson, Design and evaluation of tribological coatings, Wear. 246 (2000) 20-33.

[68] A. Öztürk, K.V. Ezirmik, K. Kazmanlı, M. Ürgen, O.L. Eryılmaz, A. Erdemir, Comparative tribological behaviors of $\mathrm{TiN}, \mathrm{CrN}$ and $\mathrm{MoNCu}$ nanocomposite coatings, Tribol. Int. 41 (2008) 49-59.

[69] F. Seibert, M. Döbeli, D.M. Fopp-Spori, K. Glaentz, H. Rudigier, N. Schwarzer, B. Widrig, J. Ramm, Comparison of arc evaporated Mo-based coatings versus $\mathrm{Cr}_{1} \mathrm{~N}_{1}$ and taC coatings by reciprocating wear test, Wear. 298-299 (2013) 14-22.

[70] R.F. Ávila, R.D. Mancosu, A.R. Machado, S.D. Vecchio, R.B. da Silva, J.M. Vieira, Comparative analysis of wear on PVD TiN and $\left(\mathrm{Ti}_{1-x} \mathrm{Al}_{\mathrm{x}}\right) \mathrm{N}$ coatings in machining process, Wear. 302 (2013) 1192-1200. 